\title{
The current status of wind and tidal in-stream electric energy resources
}

\author{
Hamed H. H. Aly, M. E. El-Hawary \\ Department of Electrical and Computer Engineering, Dalhousie University, Halifax, Nova Scotia, Canada, B3H 4R2
}

Email address:

hamed.aly@dal.ca (H. H. H. Aly), elhawary@dal.ca (M. E. El-Hawary)

\section{To cite this article:}

Hamed H. H. Aly, M. E. El-Hawary. The Current Status of Wind and Tidal in-Stream Electric Energy Resources, American Journal of Electrical Power and Energy Systems. Vol. 2, No. 2, 2013, pp. 23-40. doi: 10.11648/j.epes.20130202.11

\begin{abstract}
Renewable energy is an effective and clean source of supplying electrical loads especially in remote and rural areas. In this paper we discuss offshore wind and tidal in-stream energy as they rely on similar technologies for generating electricity at offshore sites. In particular, we survey the impacts of offshore wind and tidal current integration into the grid, various types of generators and their dynamic modeling, fault ride-through techniques used to improve generator and grid integration performance, the aggregated wind turbines modeling and finally put the light on the stability and control problems.
\end{abstract}

Keywords: Wind Power, Tidal In-Stream Power, Doubly Fed Induction Generators (DFIG), Direct Drive Permanent Magnet Synchronous Generator (DDPMSG), Power System Dynamic Stability, Power System Modeling

\section{Introduction}

Wind energy is the energy produced from the simple air in motion and this motion is caused by the uneven heating of the earth's surface by the sun. The air over the sea absorbs the heats faster than the land and so the air moves from the sea to the land causing the wind but in the night the air motion is changed from the land to the sea because the air over the sea cools faster than the air over the land. This wind is hardly predictable source of energy. Tidal energy is due to the gravitational influence of the moon and the sun on the earth due to the rotation of the earth relative to the moon and the sun which produces two high and two low waters each day ( $12.4 \mathrm{~h}$ cycle). This rotation makes the rise and fall of the tides and these tides are predictable. These tides run approximately six hours in one direction and then reverse for another six hour in the opposite direction $[1,2]$. Tidal in-stream energy has various advantages such as high energy density, hence cheap rotors for power output, predictable energy; hence its integration is easy, low environmental impact and low bird disturbance [3]. The main difference between the wind and tidal is the high density of the seawater (800 times greater than air) if it is compared to wind and this helps to use a smaller system for tidal and obtaining the same energy $[4,5]$.

While wind turbines have negative issues such as audio noise, visual impacts, erosion, birds and bats killed and radio interference, it is useful in rural area applications where access to transmission facilities is limited. Moreover, wind energy helps to reduce the environmental damage (Green house Gas emissions) and climate change due to fossil fuel replacement [6]. The wind power resource is intermittent and challenging to predict, and requires using some form of storage to integrate it in the electric grid. New control techniques and improved forecasting methods help establish operating practices which will increase reliability of wind energy supply to the grid.

The problems of wind and tidal-stream may be overcome by the advanced technology in the near future and will become from the preferred ways for obtaining electrical energy.

\section{Renewable Energy from Canadian and Nova Scotian Perspective}

Various types of renewable energy are used at present. For instance, solar energy is used directly, usually via solar panels, to heat and power homes. Similarly, the heat of the sun drives the winds to produce wind energy. The wind and the sun cause water evaporation, which turns into rain and snow and contributes to rivers and waterfalls, whose energy can be captured through hydro power turbines. The sunlight and rain cause plants to grow, and these can eventually be harvested for biomass energy. Other renewable energy 
sources are geothermal energy, which is generated and stored in the earth, and marine energy, on which this research is based.

Canada is one of the world leaders in the use of marine renewable energy due to its unique geography, abundant resources, and expertise in ocean engineering and offshore operations. Billions of tonnes of seawater ebb and flow every day along Canadian shorelines. Indeed, developing marine energy has become an integral part of government energy and economic strategy, according to one government minister who stated that "The Marine Renewable Energy Technology Roadmap demonstrates how government, industry and academics are working together to advance the commercialization of marine energy technologies in Canada while sharpening our global competitiveness" [10].

Being almost completely surrounded by seawater, the province of Nova Scotia has abundant marine renewable energy resources from offshore wind, waves and tides. The Bay of Fundy, located on the province's western shore, has a 100 billion tonnes of seawater flowing into it each day, delivering a commercial potential of approximately 2,400 megawatts of power. This massive inflow of seawater exceeds the daily combined flow of the world's freshwater rivers. The energy potential is so huge compared to other countries that one industry expert has dubbed the Bay of Fundy the "Saudi Arabia" of marine renewable energy. The United States (U.S.)-based Electric Power Research Institute (EPRI) has also identified the Bay of Fundy as a prime site for potential tidal power generations. Ocean energy presents a significant opportunity for generating electrical energy, and tidal current and wave energy technologies are at the investigative stage. The development of renewable energy in Nova Scotia will help to contribute to the longterm renewable electricity mix, reducing greenhouse gases and other air pollutants, decreasing dependence on fossil
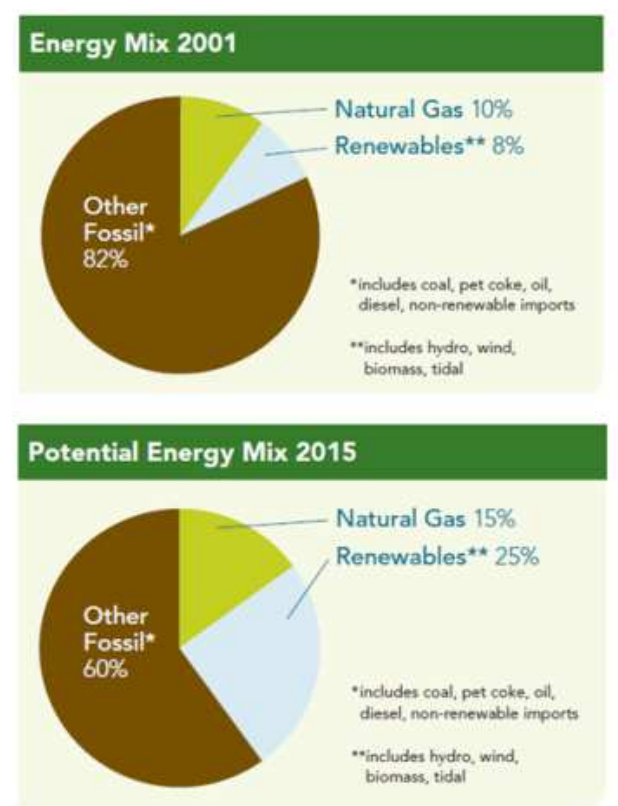

fuels, reducing emissions, providing a diverse and more secure mix of energy, producing clean, green energy, and creating employment opportunities that build wealth and exports [11].

Despite the rosy picture being painted by industry and government investors, there are several issues that must be taken into consideration when dealing with marine renewable energy as a new source of energy. These issues include the following:

1. The protection of the marine ecosystem.

2. Health, safety and environmental protection.

3. The conservation of natural resources (not economic gain) as a top priority.

4. Sustainable industry development.

As well, there are environmental impacts that must be investigated and properly handled, such as $[11,12]$ :

1. The sediments, substrates and disruption of the currents and waves.

2. Electric and magnetic field effects.

3. Noise due to turbine blade rotation.

4. Navigation impacts and water quality changes.

5. Impacts on sea and land animal migration.

Renewable energy is needed to reduce dependence on imported fossil fuels, make Nova Scotia less susceptible to fluctuating market prices, and diversify the energy mix to bring stability to electricity rates. The total amount of renewable electricity in Nova Scotia based on 12,000 $\mathrm{GWh} / \mathrm{yr}$ of total provincial electricity sales was 1100 $\mathrm{GWh} / \mathrm{yr}(9 \%) \mathrm{pre}-2001,1300 \mathrm{GWh} / \mathrm{yr}(11 \%)$ at the end of 2009 , and $1700 \mathrm{GWh} / \mathrm{yr}(14 \%)$ at 2011. It is expected to be $2300 \mathrm{GWh} / \mathrm{yr}(19 \%)$ by $2013,3000 \mathrm{GWh} / \mathrm{yr}$ (25\%) by 2015 , and $4800 \mathrm{GWh} / \mathrm{yr}(40 \%)$ by 2020 . Figure (1) shows the percentage of renewable energy compared to other sources in Nova Scotia for 2001 and 2009 and the expected percentage for 2015 and 2020 [12, 13].

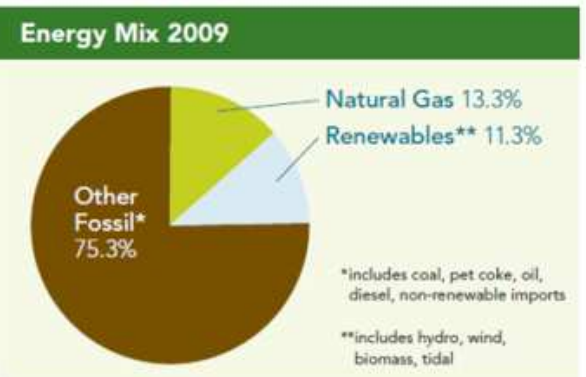

Potential Energy Mix 2020

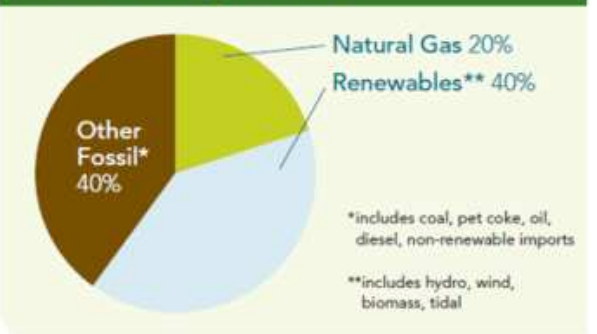

Figure 1. Potential energy mix in 2001 and 2009 and the expected potential energy mix in 2015 and 2020 [13]. 
Ocean waves produced by winds passing over the surface of the water are converted to electricity. There are approximately 50 competing designs being tested around the world in search of commercially viable wave-energy technology. The cost of wave energy is estimated by the International Energy Agency (IEA) to be in the range of $\$ 0.20$ to $\$ 0.75$ per $\mathrm{kWh}$, depending on location. Nova Scotia's best wave resources are far from land, and so the overall cost will be relatively high. Hence, other parts of the world with better waves closer to shore have a competitive advantage and wave technology is therefore considered to be a lower priority for Nova Scotia [12].

Wind power is another attractive renewable energy source, but the best winds (offshore winds) are expensive to harness. The cost of onshore wind power in Nova Scotia is in the range of $\$ 0.07$ to $\$ 0.09$ per $\mathrm{kWh}$, but onshore winds are not as constant as offshore winds. A 2011 report by the International Energy Agency put the current costs of offshore winds between $\$ 0.17$ and $\$ 0.35$ per $\mathrm{kWh}$, making it far less economical than onshore winds due to the significantly higher construction and maintenance costs associated with these projects $[11,12]$.

Marine renewable energy is a new trend for generating electricity. It is expected to create jobs and grow the economy in the near future. Tidal current energy is an ideal renewable energy source because it is more predictable than wind and solar power, and this will reduce the backup capacity and improve reliability, which potentially could be reflected in the cost.

The US-based Electric Power Research Institute estimated that underwater turbines could safely extract 300 megawatts of energy from the Minas Channel alone. In July 2011, the government of Nova Scotia announced a plan to create 'winning conditions' for the development of an instream tidal energy sector that will generate $65 \mathrm{MW}$ by 2015 and an additional $300 \mathrm{MW}$ in 5 to 10 years to replace approximately $10 \%$ of Nova Scotia's current power supply.
This amount would be more or less equivalent to Nova Scotia's existing coal-fired generation. The province has recently introduced the Renewable Electricity Plan, which sets out a detailed program to move Nova Scotia away from carbon-based electricity generation towards greener, more local sources. Power from tidal current is expected to start contributing electricity around the middle of this decade and could make a significant contribution to electricity generation by 2020 . The government currently provides support for tidal energy through FORCE (Fundy Ocean Research Centre for Energy). However, the cost of electricity from marine renewable energy resources is still so high that it is not yet competitive with other sources. This is because the technology is still in its infancy stage and many technical challenges remain to be resolved before large-scale commercial development can be implemented. Nevertheless, as the technology develops, the cost is expected to become competitive $[14,15]$.

Until now, there has been limited experience in assessing the costs associated with large-scale tidal energy. As mentioned, current costs are generally high, averaging $\$ 0.44$ to $\$ 0.51$ per $\mathrm{kWh}$ for initial deployments. Costs are even higher for smaller projects (in the range of $\$ 0.652$ per $\mathrm{kWh}$ ). Despite this financial hurdle, rising oil and coal prices along with the growing demand for clean and safe energy, are important issues bolstering the attractiveness of renewable energy. Moreover, the range of benefits and impacts created by the generation of marine renewable energy will differ depending on project location and technology used $[14,15]$. Figure (2) shows a map of the mean power that can be easily extracted from tidal current passages around Nova Scotia while reducing the volume of water flowing through the passages by $5 \%$. These values are calculated using simulation programs for tidal currents. In Cape Breton, the values are calculated using the characteristics of the flow and power extraction theory [12].

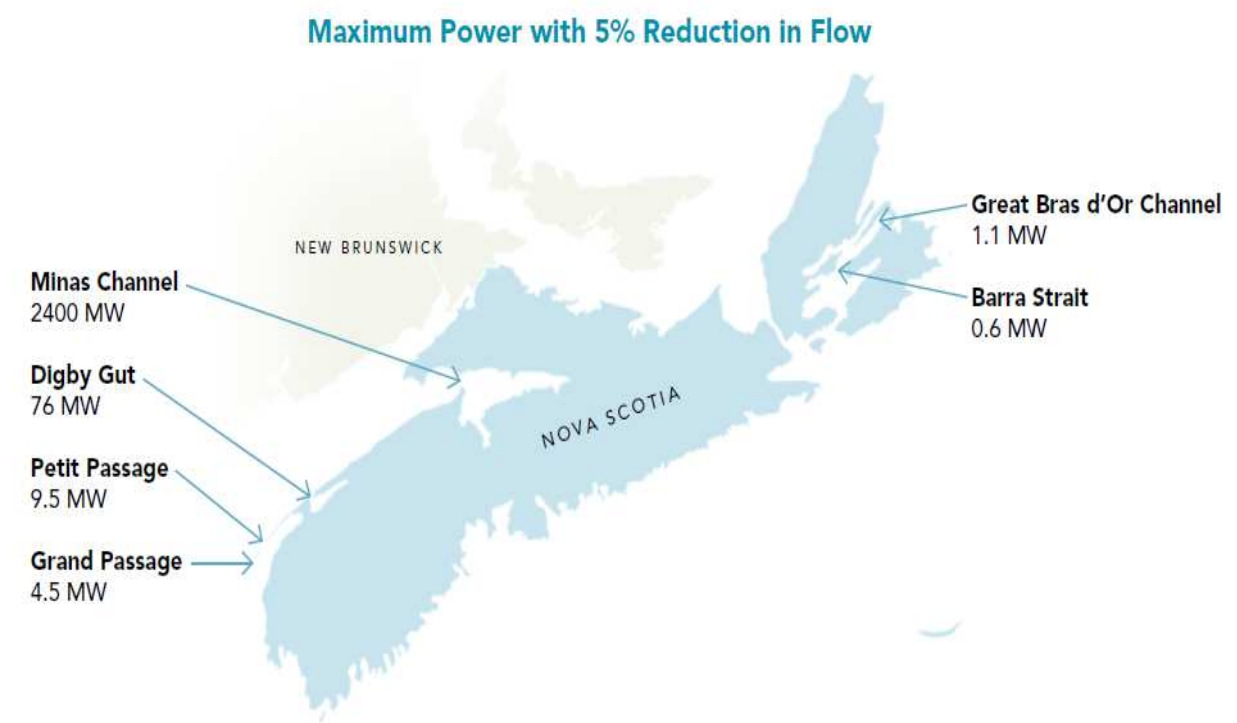

Figure 2. Map for the mean power that can be easily extracted from tidal current passages around Nova Scotia [12]. 
The federal and provincial governments have spent more than $\$ 75$ million in support of marine renewable energy development projects over the past five years. An additional $\$ 100$ million will be invested in phase 1 of FORCE, and the installation of technology arrays will involve a \$500million investment in the coming five years. From these projects, $75 \mathrm{MW}$ will be installed by $2016,250 \mathrm{MW}$ will be installed by 2020, and 2,000 MW will be installed by 2030 . It is worth noting that more than $50 \%$ of marine energy projects around the world use Canadian technology or expertise $[16,17]$.

The European Union (EU) member states have a target of deploying $1.95 \mathrm{GW}$ of marine energy by 2020 . Figure (3) shows the marine targets for EU member states, most of which are situated along the Atlantic coast (UK, Ireland, France, Spain and Portugal) [18].



Figure 3. Marine targets for EU member states [18].

\section{Offshore Wind Turbines}

This section consists of five subsections ordered as follows; the types of the wind turbines, the dynamic modeling of the wind turbine system, the integration of wind turbines in the power system grid, the stability problems of the wind turbines, its mitigation methods and finally the wind farm aggregation.

\subsection{Wind Turbine Types}

Most wind turbines are based on one of the three main wind turbine generator types as shown figure (4):

1) Fixed speed with directly grid-coupled squirrel cage induction generator (FSIG). The rotor side of the fixed speed squirrel cage induction generator (FSIG) is connected to the wind turbine via a gearbox and the other side of the generator (stator winding) is connected directly to the grid.
The speed varies in a very small range (may be considered as fixed speed) according to the generated power at variable wind changes depending on the mechanical system, hence during the fault it may lead to voltage instability, especially at low voltage. Some of the drawbacks of this approach are size, maintenance requirements, noise, lower reliability and efficiency. With the induction generator connected directly to the grid, the voltage level at the grid cannot be controlled, also blade rotation causes power variations and, this will affect the voltage and cause the frequency to vary from 1 to $2 \mathrm{~Hz}$ in the grid. The FSIG consumes reactive power and this may cause voltage issues after the fault is cleared. Compensating capacitors are used as the squirrel cage generator absorbs reactive power from the grid. The transient stability behavior of FSIG is poor and the machine must be switched off under fault conditions. [19, 20].

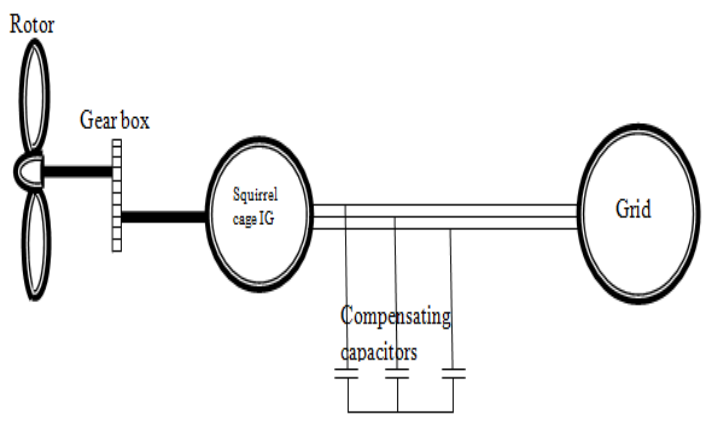

a. Fixed Speed Squirrel Cage Induction Generator

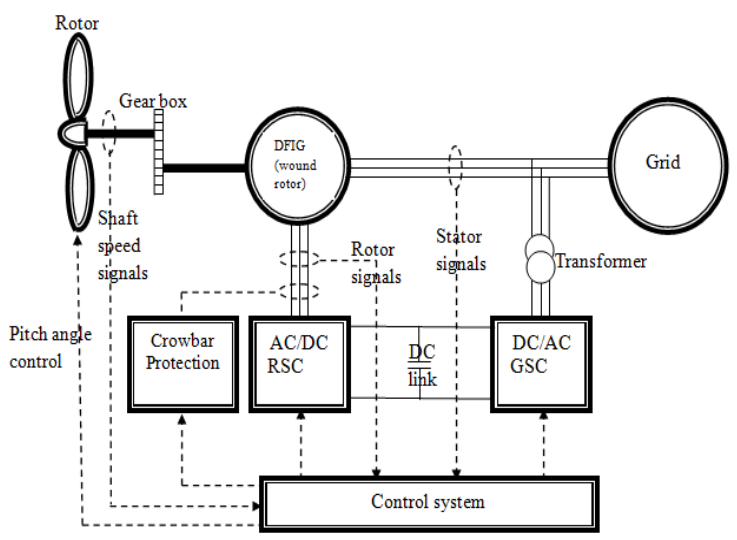

b. Doubly Fed Induction Generator

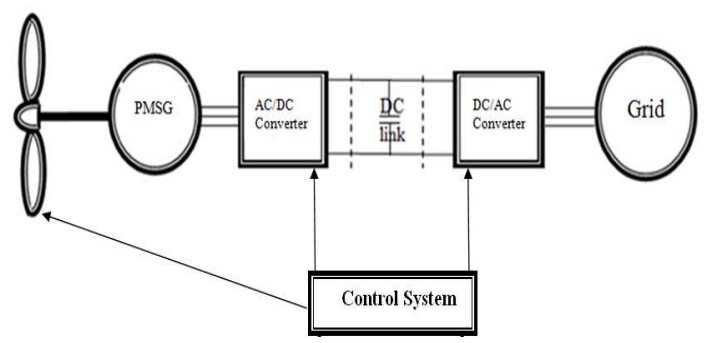

c. Direct Drive Synchronous Generator

Figure 4. Types of wind turbine.

2) Variable speed with doubly fed induction generator 
(DFIG).

In the DFIG, a converter is used to feed or take power from the rotor and gives a variable speed (a partial scale power converter used as about $20-30 \%$ of the power passes through the converter). The rotor side of the DFIG is connected to the grid via a back to back converter. The converter on the side connected to the grid is called the supply side converter (SSC) or grid side converter (GSC) while the converter connected to the rotor is the rotor side converter (RSC). The RSC operates in the stator flux reference frame. The direct axis component of the rotor current acts in the same way as the field current as in the synchronous generator and thus controls the reactive power change and the quadrature component of the rotor current is used to control the speed by controlling the torque and the active power change. Thus the RSC governs both the stator-side active and reactive powers in an independent manner.

The GSC operates in the stator voltage reference frame. The $d$-axis current of the GSC controls the DC link voltage to a constant level, and the $q$-axis current is used for reactive power control. The GSC is used to supply or draw power from the grid according to the speed of the machine. If the speed is higher than synchronous speed it supplies power, otherwise it draws power from the grid but its main objective is to keep the dc-link voltage constant regardless of the magnitude and direction of the rotor power [21]. DFIG is more stable as the rotor speeds of DFIGs is easy to be controlled by the generator side, also the active power and reactive power are controlled independently by using the converter on the rotor side, and the fluctuation of the voltage is minimized [22]. The dynamic behavior of the turbine is improved, the noise at low speed is reduced, the power production higher than FSIG and mechanical stresses reduced. The power quality in DFIG is improved but it is more complex than FSIG and the overall cost is increased due to the use of power electronic devices for control [22-25]. DFIG is the most commonly used one for wind integration due to its high efficiency, fast reaction and robustness during the fault. This machine is able to give a controlled reactive power to the grid [26].

3) Variable speed based on a direct drive synchronous generator. In the variable speed wind turbine with direct drive synchronous generator, the generator and the grid are connected by means of a converter, which is allowing variable speed operation (a full scale converter is used, 100\% of the power pass through the converter) $[22,23]$.

The gear box between the generator and the turbine has various demerits because of the size, the maintenance, the noise, the lower reliability and efficiency, so the new technologies connect the generator directly to the turbine by using numerous pairs of poles but at the same time use filters on the generator output because of high harmonic content caused by operation at low speeds [22]. Table (1) shows a comparison between three types of generators.
Table 1. A comparison between three types of generators.

\begin{tabular}{llll}
\hline Comparison & FSIG & DFIG & Synchronous \\
\hline 1-Speed & Fixed & Variable & Variable \\
2-Converter scale & Zero & $\begin{array}{l}\text { 20-30\% } \\
\text { Partially } \\
\text { via stator } \\
\text { and the }\end{array}$ & $\begin{array}{l}\text { Totally via } \\
\text { the converter }\end{array}$ \\
$\begin{array}{l}\text { 3-Power supplied } \\
\text { to the grid }\end{array}$ & Directly & converter & \\
4-Control & Poor & Good & Very good \\
$\begin{array}{l}\text { 5-Active and } \\
\text { reactive power } \\
\text { control }\end{array}$ & $\begin{array}{l}\text { Dependent } \\
\text { 6-Voltage } \\
\text { fluctuation }\end{array}$ & Independent & Independent \\
6-Robustness & High & Limited & Limited \\
7-Fault reaction & Slow & High & Very high \\
8-Efficiency & Poor & High & High \\
9-Cost & Low & High & High \\
\hline
\end{tabular}

\subsection{Dynamic Modeling of the wind Turbine System}

The dynamic modeling of the overall wind turbine system contains all subsystems such as wind speed model that is used for generating a wind speed signal applied to the rotor, the rotor model, the generator, the converter, the rotor speed controller, the pitch angle controller (for changing the blade pitch angle to control the amount of energy during high speeds), the voltage controller (for controlling the voltage near the reference value), and the protection system (for the protection of wind turbine) [27-28]. Figure (5) shows the overall wind turbine system and their interaction.

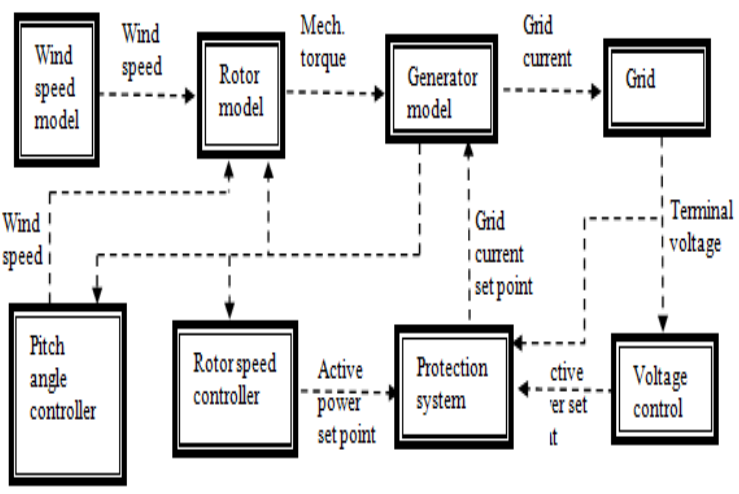

Figure 5. Overall wind turbine system and their interaction.

1) The Wind Speed Signals $\left(v_{w}\right)$

The wind speed signals model consists of four components, the mean wind speed $\left(\mathrm{v}_{\mathrm{mw}}\right)$, the wind speed ramp $\left(\mathrm{v}_{\mathrm{rw}}\right)$ (which is considered as the steady increase in the mean wind speed), the wind speed gust $\left(\mathrm{v}_{\mathrm{gw}}\right)$, and the turbulence $\left(\mathrm{v}_{\mathrm{tw}}\right) . \quad \mathrm{v}_{\mathrm{w}}=\mathrm{v}_{\mathrm{mw}}+\mathrm{v}_{\mathrm{gw}}+\mathrm{v}_{\mathrm{rw}}+\mathrm{v}_{\mathrm{tw}}$. The mean wind speed is a constant speed; a simple ramp function will be used for ramp component (characterized by the amplitude of the wind speed $\operatorname{ramp}\left(\mathrm{A}_{\mathrm{r}}(\mathrm{m} / \mathrm{s})\right)$, the starting time $\left(\mathrm{T}_{\mathrm{sr}}\right)$, and the 
ending time $\left.\left(\mathrm{T}_{\mathrm{er}}\right)\right)$. The wind speed gust component is characterized by the amplitude of the wind speed gust $\left(\mathrm{A}_{\mathrm{g}}\right.$ $(\mathrm{m} / \mathrm{s}))$, the starting time $\left(\mathrm{T}_{\mathrm{sg}}\right)$, and the ending time $\left(\mathrm{T}_{\mathrm{eg}}\right)$. The wind speed gust may be expressed as a sine, cosine wave function or a combination of both. One of the most used models is expressed as:

$$
\begin{gathered}
v_{g w}=\mathrm{A}_{\mathrm{g}}\left(1-\cos \left(2 \Pi\left(\mathrm{t} / \mathrm{D}_{\mathrm{g}}-\mathrm{T}_{\mathrm{sg}} / \mathrm{D}_{\mathrm{g}}\right)\right)\right) \\
\mathrm{T}_{\mathrm{sg}} \leq \mathrm{t} \leq \mathrm{T}_{\mathrm{eg}} \\
v_{g w}=0, \mathrm{t}<\mathrm{T}_{\mathrm{sg}} \text { or } \mathrm{t}>\mathrm{T}_{\mathrm{eg}} \\
, \mathrm{D}_{\mathrm{g}}=\mathrm{T}_{\mathrm{eg}}-\mathrm{T}_{\mathrm{sg}} .
\end{gathered}
$$

A triangle wave is used for the turbulence function which has adjusted frequency and amplitude [28, 29].

2) The Rotor Model

The rotor model is used for converting the kinetic energy to mechanical energy. The wind turbine is characterized by $C_{p}$ (wind power coefficient), $\lambda$ (tip speed ratio), and $\beta$ (pitch angle). $\lambda=\omega_{t} R / v_{w}$, where $R$ is the blade length in $\mathrm{m}, v_{w}$ is the wind speed in $\mathrm{m} / \mathrm{s}$, and $\omega_{t}$ is the wind turbine rotational speed in $\mathrm{rad} / \mathrm{sec}$. $C_{P}-\lambda-\beta$ curves differ from manufacturer to another but there is an approximate relation for these curves as shown: $\quad C_{p}=\frac{1}{2}\left(\frac{R C_{f}}{\lambda}-0.026 \beta-\right.$ 2) $e^{-0.295 \frac{R C_{f}}{\lambda}}$

, $\mathrm{C}_{\mathrm{f}}$ is the wind turbine blade design constant.

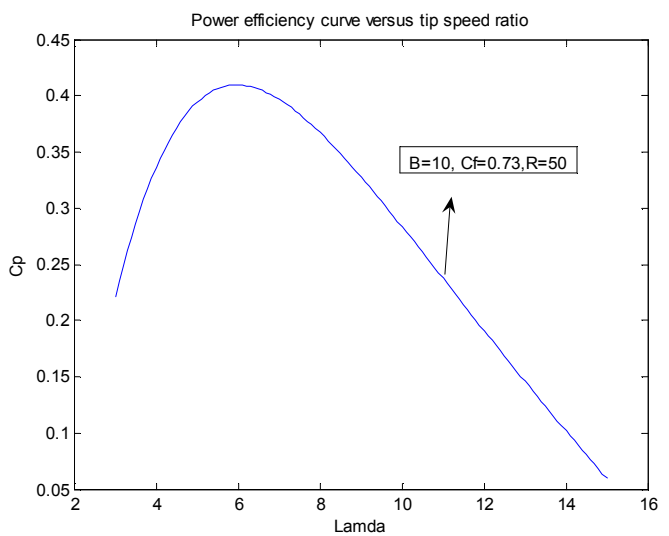

Figure 6. The relation between e wind power efficiency and tip speed ratio.

The rotor model may be represented by using the equation of the power extracted from the wind as follows:

$$
\mathrm{P}_{\mathrm{w}}=0.5 \rho \Pi R^{2} C_{p} v_{w}^{3}
$$

And the mechanical torque applied to the turbine $\left(\mathrm{T}_{\mathrm{m}}\right)$ can be expressed as: $\mathrm{T}_{\mathrm{m}}=0.5 \rho \Pi R^{2} C_{p} v_{w}^{3} / v_{m}$

Where: $v_{\mathrm{m}}$ is the turbine speed at hub height upstream the rotor, $\rho$ is the density of the air [29].

The shaft system may be represented by a two mass system (two mass model is represented, one for the turbine and the other for the generator) or by a single lumped mass system.

The two mass systems may be represented as:

$$
\begin{gathered}
2 \mathrm{H}_{\mathrm{t}} \frac{d \omega_{t}}{d t}=\mathrm{T}_{\mathrm{t}}-\mathrm{K}_{\mathrm{s}}\left(\square_{\mathrm{r}}-\square_{\mathrm{t}}\right)-\mathrm{D}_{\mathrm{m}}\left(\omega_{\mathrm{r}}-\omega_{\mathrm{t}}\right) \\
2 \mathrm{H}_{\mathrm{g}} \frac{d \omega_{g}}{d t}=-\mathrm{T}_{\mathrm{e}}+\mathrm{K}_{\mathrm{s}}\left(\square_{\mathrm{g}}-\square_{\mathrm{t}}\right)-\mathrm{D}_{\mathrm{m}}\left(\omega_{\mathrm{g}}-\omega_{\mathrm{t}}\right)
\end{gathered}
$$

Where: $D_{t}$ is the turbine self-damping, $D_{g}$ is the generator self damping, $\mathrm{D}_{\mathrm{m}}$ is the mutual damping, $\mathrm{H}_{t}$ and $\mathrm{H}_{\mathrm{g}}$ are the turbine and generator inertia constants, respectively, $\mathrm{K}_{\mathrm{s}}$ is the shaft stiffness, $\omega_{\mathrm{t}}$ and $\omega_{\mathrm{g}}$ the turbine and generator rotor speeds. $\square_{\mathrm{t}}$ and $\square_{\mathrm{g}}$ denote the turbine and generator rotor angles. There is a ratio of the torsion angles, damping and stiffness must be taken into account when one add the gear box as all above calculations must be referred to the generator and then calculated as follows[30].

$$
\begin{gathered}
\mathrm{a}=\frac{\omega_{g}}{\omega_{t}}, \omega_{t}^{(t)}=\frac{\omega_{t}^{(g)}}{a}, \underset{t}{(t)}=\frac{(g)}{a} \\
K_{s}^{(t)}=\mathrm{a}^{2} K_{s}^{(g)}, D_{m}^{(t)}=\mathrm{a}^{2} D_{m}^{(g)}
\end{gathered}
$$

One may express the shaft system as a single lumped mass as follows: $2 \mathrm{H}_{\mathrm{m}} \frac{d \omega_{m}}{d t}=\mathrm{T}_{\mathrm{m}}-\mathrm{T}_{\mathrm{e}}-\mathrm{D}_{\mathrm{m}} \omega_{\mathrm{m}}$, where, $\mathrm{T}_{\mathrm{e}}$ is the electrical torque of the generator, $H_{m}$ is the lumped inertia constant, $\omega_{\mathrm{m}}$ is the rotational speed of the lumped mass system, and $\mathrm{D}_{\mathrm{m}}$ is the damping of the lumped system.

3) The Generator Model

a) DFIG model: The modeling of the DFIG is developed by using a synchronously rotating $d-q$ reference frame with the direct -axis oriented along the stator flux position. The reference frame is rotating with the same speed as the stator voltage. The stator and rotor active and reactive power can be described as $[25,31-40]: \mathrm{P}_{\mathrm{s}}=3 / 2\left(\mathrm{v}_{\mathrm{ds}} \times \mathrm{i}_{\mathrm{ds}}+\mathrm{v}_{\mathrm{qs}} \times \mathrm{i}_{\mathrm{qs}}\right)$,

$$
\begin{gathered}
\mathrm{P}_{\mathrm{r}}=3 / 2\left(\mathrm{v}_{\mathrm{dr}} \times \mathrm{i}_{\mathrm{dr}}+\mathrm{v}_{\mathrm{qr}} \times \mathrm{i}_{\mathrm{qr}}\right), \\
\mathrm{P}_{\mathrm{g}}=\mathrm{P}_{\mathrm{s}}-\mathrm{P}_{\mathrm{r}} \\
\mathrm{Q}_{\mathrm{s}}=3 / 2\left(\mathrm{v}_{\mathrm{qs}} \times \mathrm{i}_{\mathrm{ds}}-\mathrm{v}_{\mathrm{ds}} \times \mathrm{i}_{\mathrm{qs}}\right), \\
\mathrm{Q}_{\mathrm{r}}=3 / 2\left(\mathrm{v}_{\mathrm{qr}} \times \mathrm{i}_{\mathrm{dr}}+\mathrm{v}_{\mathrm{dr}} \times \mathrm{i}_{\mathrm{qr}}\right)
\end{gathered}
$$

The model of the DFIG can be described as:

$$
\begin{gathered}
\mathrm{v}_{\mathrm{ds}}=-\mathrm{R}_{\mathrm{s}} \mathrm{i}_{\mathrm{ds}}-\omega_{\mathrm{s}} \Psi_{\mathrm{qs}}+\frac{\mathrm{d}}{\mathrm{dt}} \Psi_{\mathrm{ds}} \\
\mathrm{v}_{\mathrm{qs}}=-\mathrm{R}_{\mathrm{s}} i_{\mathrm{qs}}+\omega_{\mathrm{s}} \Psi_{\mathrm{ds}}+\frac{\mathrm{d}}{\mathrm{dt}} \Psi_{\mathrm{qs}} \\
\mathrm{v}_{\mathrm{dr}}=-\mathrm{R}_{\mathrm{r}} \mathrm{i}_{\mathrm{dr}}-\mathrm{s} \omega_{\mathrm{s}} \Psi_{\mathrm{qr}}+\frac{\mathrm{d}}{\mathrm{dt}} \Psi_{\mathrm{dr}} \\
\mathrm{v}_{\mathrm{qr}}=-\mathrm{R}_{\mathrm{r}} \mathrm{i}_{\mathrm{qr}}+\mathrm{s} \omega_{\mathrm{s}} \Psi_{\mathrm{dr}}+\frac{\mathrm{d}}{\mathrm{dt}} \Psi_{\mathrm{qr}} \\
\Psi_{d s}=-L_{s s} i_{d s}-L_{m} i_{d r}, \Psi_{q s}=-L_{s s} i_{q s}-L_{m} i_{q r} \\
\Psi_{d r}=-L_{r r} i_{d r}-L_{m} i_{d s}, \Psi_{q r}=-L_{r r} i_{q r}-L_{m} i_{q s} \\
\mathrm{~s}=\left(\omega_{\mathrm{s}}-\omega_{\mathrm{r}}\right) / \omega_{\mathrm{s}} \\
\frac{d \omega_{r}}{d t}=-\omega_{\mathrm{s}} \frac{d s}{d t}
\end{gathered}
$$

, where: $d$, and $q$ are the indices of the direct and quadrature axis components, $\mathrm{s}$, and $\mathrm{r}$ are the indices of the stator and the rotor, $v$ is the voltage, $R$ is the resistance, $i$ is the 
current, $\omega_{s}, \omega_{r}$ are the stator and rotor electrical angular velocities $(\mathrm{rad} / \mathrm{s})$, respectively, and $\psi$ is the flux linkage. The converter in the grid side controls the dc-link voltage, regardless of the magnitude and direction of the rotor power and the converter in the rotor side controls the rotor currents. $L_{s s}=L_{s}+L_{m}, L_{r r}=L_{r}+L_{m}, L_{s}, L_{r}$ and $L_{m}$ are the stator leakage, rotor leakage and mutual inductances, respectively. For the DFIG the rotor is connected to the grid via a converter, hence: $v_{d r}=v_{d c}, \quad v_{q r}=v_{q c}$. It is easy to find the state space representation of the induction machine as $\frac{d[i]}{d t}=[A][i]+[B][v]$, (by substituting $\psi$ into the equation of $v$ ) or as $\frac{d[\Psi]}{d t}=[A][\Psi]+[B][v]$.

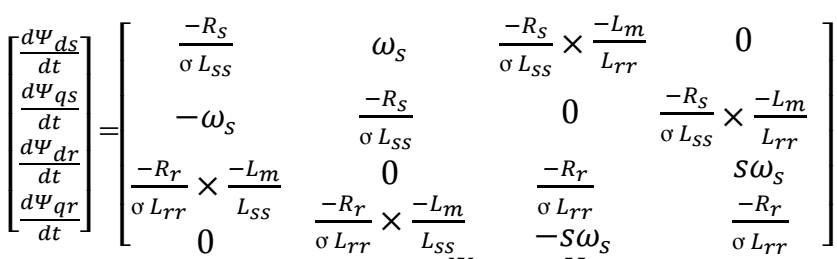

$$
\begin{aligned}
& \times\left[\begin{array}{c}
\Psi_{d s} \\
\Psi_{q s} \\
\Psi_{d r} \\
\Psi_{q r}
\end{array}\right]+\left[\begin{array}{c}
V_{d s} \\
V_{q s} \\
V_{d r} \\
V_{q r}
\end{array}\right], O=\frac{L_{s s} L_{r r}-L_{m}^{2}}{L_{s s} L_{r r}}
\end{aligned}
$$

Under the steady state conditions one may write the stator and the rotor equations as follows:

$$
\begin{aligned}
& \mathrm{v}_{\mathrm{ds}}=-\mathrm{R}_{\mathrm{s}} \times \mathrm{i}_{\mathrm{ds}}-\mathrm{J} \omega_{\mathrm{s}} \times\left(-\mathrm{L}_{\mathrm{ss}} \times \mathrm{i}_{\mathrm{qs}}+\mathrm{L}_{\mathrm{m}} \times \mathrm{i}_{\mathrm{qr}}\right)+\frac{d}{d t} \psi_{d s} \\
& \mathrm{v}_{\mathrm{qs}}=-\mathrm{R}_{\mathrm{s}} \times \mathrm{i}_{\mathrm{qs}}+\mathrm{J} \omega_{\mathrm{s}} \times\left(-\mathrm{L}_{\mathrm{ss}} \times \mathrm{i}_{\mathrm{ds}}+\mathrm{L}_{\mathrm{m}} \times \mathrm{i}_{\mathrm{dr}}\right)+\frac{d}{d t} \psi_{q s} \\
& \mathrm{v}_{\mathrm{dr}}=\mathrm{R}_{\mathrm{r}} \times \mathrm{i}_{\mathrm{dr}}-\mathrm{s} \times \mathrm{J} \omega_{\mathrm{s}} \times\left(\mathrm{L}_{\mathrm{rr}} \times \mathrm{i}_{\mathrm{qr}}-\mathrm{L}_{\mathrm{m}} \times \mathrm{i}_{\mathrm{qs}}\right)+\frac{d}{d t} \psi_{d r} \\
& \mathrm{v}_{\mathrm{qr}}=\mathrm{R}_{\mathrm{r}} \times \mathrm{i}_{\mathrm{qr}}+\mathrm{s} \times \mathrm{J} \omega_{\mathrm{s}} \times\left(\mathrm{L}_{\mathrm{rr}} \times \mathrm{i}_{\mathrm{dr}}-\mathrm{L}_{\mathrm{m}} \times \mathrm{i}_{\mathrm{ds}}\right)+\frac{d}{d t} \psi_{q r}
\end{aligned}
$$

The $5^{\text {th }}$ order model may be reduced to a $3^{\text {rd }}$ order by neglecting the stator transients and described it as follows:

$$
\begin{gathered}
\mathrm{v}_{\mathrm{ds}}=-\mathrm{R}_{\mathrm{s}} \times \mathrm{i}_{\mathrm{ds}}+\mathrm{X} \square \times \mathrm{i}_{\mathrm{qs}}+\mathrm{e}_{\mathrm{d}} \\
\mathrm{v}_{\mathrm{qs}}=-\mathrm{R}_{\mathrm{s}} \times \mathrm{i}_{\mathrm{qs}}-\mathrm{X} \square \times \mathrm{i}_{\mathrm{ds}}+\mathrm{e}_{\mathrm{q}} \\
2 \mathrm{H}_{\mathrm{g}} \frac{d \omega_{r}}{d t}=\mathrm{T}_{\mathrm{e}}-\mathrm{T}_{\mathrm{m}}
\end{gathered}
$$

Where

$$
\begin{aligned}
& \frac{d e_{d}}{d t}=-\frac{1}{T_{0}}\left(e_{d}-\right.\left.(X-X) \times i_{q s}\right)+s \times \omega_{s} \times e_{q}- \\
& \omega_{s} \times \frac{L_{m}}{L_{r r}} \times v_{q r}, \\
& \frac{d e_{q}}{d t}=-\frac{1}{T_{0}}\left(e_{q}-(X-X) \times i_{d s}\right)-s \times \omega_{s} \times e_{d}+ \\
& \omega_{s} \times \frac{L_{m}}{L_{r r}} \times v_{d r},
\end{aligned}
$$

the components of the voltage behind the transient (the internal voltage components of the induction generator) are $e_{d}=-\frac{\omega_{s} L_{m}}{L_{r r}} \times \psi_{q r}$ and $e_{q}=\frac{\omega_{s} L_{m}}{L_{r r}} \times \psi_{d r}$. The stator reactance $\mathrm{X}=\omega \mathrm{s} \mathrm{Lss}=\mathrm{Xs}+\mathrm{Xm}$, and the stator transient reactance $\mathrm{X} \square=\omega \mathrm{s}(\mathrm{Lss}-\mathrm{Lm} 2 / \mathrm{Lrr})=\mathrm{Xs}+(\mathrm{Xr} \times \mathrm{Xm}) /(\mathrm{Xr}$
$+\mathrm{Xm})$. The transient open circuit time constant is To $=$ $\mathrm{Lrr} / \mathrm{Rr}=(\mathrm{Lr}+\mathrm{Lm}) / \mathrm{Rr}$, and the electrical torque is $\mathrm{Te}=(\mathrm{id}-$ siqr-iqsidr)Xm $/ \omega_{s}$.

The $3^{\text {rd }}$ order model doesn't give details about the transient but it is interesting in the dynamic studies of large power system as it reduces the computational time.

b) SCIG modeling: In the SCIG the rotor is short circuited and so, the stator voltages are the same as the DFIG:

$$
\begin{aligned}
& v_{d s}=-R_{s} \times i_{d s}-\omega_{s} \times \psi_{q s}+\frac{d}{d t} \psi_{d s} \\
& v_{q s}=-R_{s} \times i_{q s}+\omega_{s} \times \psi_{d s}+\frac{d}{d t} \psi_{q s}
\end{aligned}
$$

The rotor voltages:

$$
\begin{gathered}
0=\mathrm{R}_{\mathrm{r}} \times \mathrm{i}_{\mathrm{dr}}-\mathrm{s} \times \omega_{\mathrm{s}} \times \psi_{\mathrm{qr}}+\frac{d}{d t} \psi_{d r} \\
0=\mathrm{R}_{\mathrm{r}} \times \mathrm{i}_{\mathrm{qr}}+\mathrm{s} \times \omega_{\mathrm{s}} \times \psi_{\mathrm{dr}}+\frac{d}{d t} \psi_{q r} \\
\mathrm{P}_{\mathrm{r}}=0 ; \mathrm{Q}_{\mathrm{r}}=0
\end{gathered}
$$

Finally the equation of motion is $2 \mathrm{H}_{\mathrm{g}} \frac{d \omega_{r}}{d t}=\mathrm{T}_{\mathrm{e}}-\mathrm{T}_{\mathrm{m}}$.

In the SCIG there are capacitors to provide the induction generator magnetizing current and for compensation. The current injected by a SCIG at the generated node is expressed as: $\mathrm{i}_{\mathrm{dg}}=\mathrm{ids}+\mathrm{i}_{\mathrm{dc}}, \mathrm{i}_{\mathrm{qg}}=\mathrm{i}_{\mathrm{qs}}+\mathrm{i}_{\mathrm{qc}}, \mathrm{i}_{\mathrm{dc}}=\mathrm{v}_{\mathrm{qc}} / \mathrm{x}, \mathrm{i}_{\mathrm{qc}}=\mathrm{v}_{\mathrm{dc}} / \mathrm{x}$ [28].

c) The DDPMSG can be modeled as follows $[42,43]$ :

$$
\begin{aligned}
& \mathrm{v}_{\mathrm{ds}}=-\mathrm{R}_{\mathrm{s}} \times \mathrm{i}_{\mathrm{ds}}-\omega_{\mathrm{s}} \times \psi_{\mathrm{qs}}+\frac{\mathrm{d}}{\mathrm{dt}} \psi_{\mathrm{ds}} \\
& \mathrm{v}_{\mathrm{qs}}=-\mathrm{R}_{\mathrm{s}} \times \mathrm{i}_{\mathrm{qs}}+\omega_{\mathrm{s}} \times \psi_{\mathrm{ds}}+\frac{\mathrm{d}}{\mathrm{dt}} \psi_{\mathrm{qs}}
\end{aligned}
$$

The flux linkages and the torque can be expressed as:

$$
\begin{aligned}
& \Psi_{\mathrm{ds}}=-\mathrm{L}_{\mathrm{d}} \times \mathrm{i}_{\mathrm{ds}}+\psi_{\mathrm{f}} \\
& \Psi_{\mathrm{qs}}=-\mathrm{L}_{\mathrm{q}} \times \mathrm{i}_{\mathrm{qs}} \\
& \mathrm{T}_{\mathrm{e}}=(3 / 2) \mathrm{pi}_{\mathrm{qs}}\left(\left(\mathrm{L}_{\mathrm{d}}-\mathrm{L}_{\mathrm{q}}\right) \mathrm{i}_{\mathrm{ds}}+\psi_{\mathrm{f}}\right)
\end{aligned}
$$

$L_{d}$, and $L_{q}$ are the direct and quadrature inductances of the stator. $\Psi_{\mathrm{f}}$ is the excitation field linkage, and $p$ is the number of pole pairs. Figure (4.8) shows the d-q axis component of the DDPMSG. In this work for simplicity we assume that $L_{d}=L_{q}=L_{s}$, because the difference is very small as we discussed in the introduction before, and so the generator model can be rewritten in a state space representation as:

$$
\begin{gathered}
\mathrm{L}_{\mathrm{s}} \frac{d}{d t} i_{d s}=-\mathrm{v}_{\mathrm{ds}}-\mathrm{R}_{\mathrm{s}} \times \mathrm{i}_{\mathrm{ds}}+\mathrm{L}_{\mathrm{s}} \times \omega_{\mathrm{s}} \times i_{q s} \\
\mathrm{~L}_{\mathrm{s}} \frac{d}{d t} i_{q s}=-\mathrm{v}_{\mathrm{qs}}-\mathrm{R}_{\mathrm{s}} \times \mathrm{i}_{\mathrm{qs}}-\mathrm{L}_{\mathrm{s}} \times \omega_{\mathrm{s}} \times i_{d s}+\omega \times \psi_{\mathrm{f}}
\end{gathered}
$$

4) The rotor speed controller uses a power-speed curve to compute the reference power according to the actual speed.

5) The pitch angle controller model is active during the high wind speed to change the blade pitch angle to reduce $\mathrm{Cp}$. The optimal pitch angle is zero below the nominal wind speed. The maximum rate of change is within 3 to $10 \mathrm{o} / \mathrm{s}$, 
depending on the size of the wind turbine. The pitch angle controller has a low frequency, of 1 to $3 \mathrm{~Hz}$ [28].

6) The voltage controller model is used to control the value of the terminal voltage $\mathrm{v}_{\mathrm{dr}}$ by controlling the value of the reactive power as the reactive power is proportionally related to the terminal voltage [28]. The rotor side converter (RSC) is known as a controlled voltage source in which the $\mathrm{q}$ axis voltage vqr is controlling the rotor speed and the $\mathrm{d}$ axis voltage $\mathrm{v}_{\mathrm{dr}}$ is controlling the reactive power but the grid side converter (GSC) is represented by a controlled current source, and provides the exchange of active power from the rotor circuit to the grid with unity power factor [41].

7) The protection system model consists of a two parts (that they switches off the wind turbine for the deviated voltage and for the deviated frequency) and a converter current limiter to protect the semiconductor switches (its boundaries are calculated depending on the maximum amount of the reactive power generated from the wind turbine and by using the nominal value of the active power and the voltage). The aims of the control system of the DFIG are to maximize the extracted power for a wide range of speed (power optimization), limit the output power to the rated for high speeds (power limitation), and adjust the active and the reactive powers (power regulation) to a specified value according to the power system operator [28].

\subsection{Wind Integration and Mitigation Methods}

Although, the conventional power plants are still necessary because of the low availability of wind turbines and their small contribution to reliability of the power system and tidal in-stream is still under development, the use of wind energy as a domestic energy resource is an important issue especially in rural areas and the growth of the wind is very fast. However, the use of wind power alone is not preferred [44]. Wind power is fluctuating, hardly predictable, and intermittent, so it is difficult to match the generation to the demand and there is impact of this power source on the transmission system (the medium and low voltage subsystems). Hence the influences of increasing wind energy generation weaken the system and render it vulnerable to power quality perturbations unless an extra reserve generation, storage batteries, new control techniques and forecasting methods are used to help for designing operating practice which will minimize these impacts and increasing reliability of wind energy on the grid [45-47]. The induction generator which is used in wind turbines may consume reactive power and if there is no compensation method this will lead to lagging power factor results. These generators are different from the conventional as the conventional used synchronous generators which are able to work during and after the fault remove and this also effects on the transmission capacity. Integration of the wind power turbines into a weak distribution grid requires an evaluation of the grid conditions by taking into account the wind turbine characteristics as this will affect on the quality of the system and its stability [48].

\subsubsection{Grid Integration Aspects}

Successful integration of wind power into the grid requires solving some problems based on analytical studies to ensure system integrity, including [49]:

1. Power flow to ensure that lines and equipment are not overloaded or that their thermal limits are not exceeded.

2. Short circuit levels and values must be re-evaluated.

3. Transient stability margins need to be re-evaluated

4. Protection schemes need to be re-adjusted (constant speed turbines may require higher reactive power under fault conditions which may cause voltage collapse. This problem can be overcome by using dynamic reactive power sources. Variable speed wind turbines, however, restart normally following fault clearance and therefore do not have this problem. The problem with variable speed wind turbines is that they are disconnected when the fault occurs and this problem can be overcome by using specific ridethrough arrangements.

5. A controllable energy source must be available in the system to compensate for the fluctuation of wind power.

6 . The quality of power delivered to the system should be evaluated.

There are two main challenges for the wind integration into the power system, the intermittency and the grid reliability. The integration of small scale wind into the grid is not complicated as a large one [50].

\subsubsection{Methods Used for Dealing with the Large Scale Wind Integration into The Grid}

1) Revision of the methods for calculation of available transmission capacity (these methods depend on the country and the weather).

2) Transmission network reinforcement (by increasing the tensile stress of conductors, increasing the height of the towers, installing conductors with the higher load ability using capacitors, and using facts devices that have a great effect on the load flow ).

3) Convert the power lines from HVAC to HVDC which will increase the rating of the power transmitted 2-3 times and also reduce the losses of the transmission lines or built a new transmission with high capacity but this method is time consuming.

4) Excess wind energy curtailments and excess wind energy storage in hydro reservoirs (this is can be done by making a coordination between the wind and the hydro energy stations).

For the wind farm not all wind turbine generators work at the same speed and so the maximum power production of the wind farm is less than the sum of the rated power production of each one. The peak of the wind turbine may not be at the same time of the peak of the transmission lines and the wind turbines works at a full rate power for a small time and this must be taken into account when one calculates the transmission lines capacity limits for wind integration [51]. 
There are some probabilistic indices that are useful for assessment of wind energy penetration from the point of view of reliability and the cost also, such as the expected wind energy supplied (EWES) which measures the use of wind energy instead of the conventional, the expected surplus wind energy (ESWE) which measures the reserve energy that is not used, and wind utilization factor (WUF) which is the ratio of EWES of the total wind energy. These indices are very important as the random fluctuation of the wind effects on the system stability and to solve this problem there might be some constraints on the penetration of wind energy by using previous indices [52].

\subsection{Stability Problems of Wind turbines, Mitigation Me- thods and Some of the Used Control Schemes}

The integration of wind energy effects on the stability of the grid, various problems are appearing, and some of them are described below:

1) As the penetration of the FSIG increases the transient stability decreases specially without using AVR and this may lead to instability conditions. On the contrary, the DFIG and the converter synchronous generators are more stable with or without AVR as there is the ability to control the active, reactive power and the terminal voltage. The full converter synchronous generator is more stable than the DFIG but it has a high cost. The use of AVR improved the stability margin in all types of generators. During the fault conditions as the number of the FSIG penetration increases the swing angle of the conventional synchronous generator increased because the increased FSIG increases the wanted reactive power and this will increase the amount of the wanted current, consequently the voltage drop increased. But after removing the fault the FSIG is still taking a huge amount of reactive power due to its inertia and this will reduce the voltage at the conventional generator also after removing the fault and so the increased penetration of the FSIG will affect on the stability. In contrary the DFIG penetration doesn't decrease the voltage profile for the conventional generators during and after removing the fault [53].

2) For the FSIG as the number of turbines increased the voltage at the PCC will decrease, also the torque speed characteristics will be in a small zone, hence the stability will be worse. On contrary for the DFIG as the number of turbines increased the stability will increase (because of the impedance change the DFIG will supply more reactive power around the synchronous slip) but at sub-synchronous speed (away from a zero slip) DFIG will require a higher voltage control [54].

3) In the FSIG the reactive power and the grid voltage level cannot be controlled, also the blade rotation causes power variations and, this will affect on the voltage. FSIG consumes reactive power through capacitors and this may cause voltage collapse after the fault cleared.

4) The transient stability behavior of FSIG is poor; this machine may loss the synchronism and must be switched off during the fault.
5) Fault in the power system may cause voltage sag at the connection point of the wind turbine and this will increase the current in the stator winding of DFIG, hence the current will also increase in the rotor due to the magnetic coupling, causing the destruction of the power electronic converters so in DFIG there is a protection system called crowbars which will disconnect the connection to the grid $[25,36]$.

6) Doubly feed induction generators (DFIGs) improve the transient stability margins if they are connected to low voltage ride through capability, reactive current boosting and fast voltage control. However, the wind source is connected to lower levels so the reactive losses are so high, hence the reactive contribution of wind energy is limited, as a result its integration have a negative impact on the transient stability. Their speed fluctuation is slow compared to time frame and it has not a direct effect on the transient stability but has an indirect effect as the wind energy is not predictable, hence it requires a higher spinning reserve and this adds inertia to the system [55].

7) The conversion control methods for wind energy using converters effect on its frequency specially frequencies between 2 and $8 \mathrm{~Hz}$ which may cause flicker in the grid and it is preferred to dampen these frequencies in the output power. There are various control methods which describe this phenomenon from which; optimal rotational speed control which concentrate on giving maximum power and the wind rotor at the rotor speed, torque control, average power control and stochastic dynamic optimization [56].

\subsubsection{There are various methods used to mitigate the sta- bility problem among}

1) The wind generation with energy storage devices in the distribution systems may result in decreased of distribution losses and this depends on the generation relative to the local load. If this ratio is high the losses will increase. The use of storage energy is important to optimize the operation; it can be used to shift the generation to maintain the loading at optimal value [57].

2) The most effective way for improving the use of wind energy for security at steady state is to use energy storage. Energy storage is used to make the supply independent of time and this storage are used to deliver or accept energy from the grid if there is a shortage or a surplus and so at the peak load they deliver energy to the grid, hence it is the economical point also [58].

3) A DC link voltage boost scheme of insulated-gate bipolar transistors (IGBT) inverters for wind extraction is used to overcome the shortage in the voltage due to wind energy decreasing by adding a switch between one of the rectifier input legs and the middle point of the dc link reservoir capacitor and this switch turned on during the shortage and so double the value of the voltage and this method is called Patent pending. But this method makes an unsymmetrical operation, and this will bring a mechanical vibration on the wind turbine due to unsymmetrical and unbalanced operation, so it is preferred to use symmetrical 
double voltage rectifier [59].

4) Dealing with Wind fluctuations: many methods are used to handle wind energy fluctuations. In terms of placement, the methods are divided into three categories:

a- At the wind turbine generator using two windings one of which is activated at high wind levels and the other is activated for low wind levels. Using shunt capacitors and/or another inverter to provide capacitive voltage support,

b- At the DC link (DC step up chopper or voltage boost rectifier), or

c- At the inverter output by using a step up transformer [60].

5) During the fault if all wind turbines disconnect from the grid this will affect on the overall stability, hence there must be a solution for this problem by decreasing the current through the rotor by using resistors. During longer voltage dips the rotor may feed a reactive power to the grid during the fault [25].

6) The wind farm stability is improved by increasing the shaft stiffness and/or moment of inertia of the generator rotor, reducing the impedance of the line between the wind farm and the network, and improving the operating power factor of the wind farm $[61,62]$.

From the above discussion one concludes that the fault in the power system is the most commonly problematic effects on the operation of the conventional generators and also the wind power generators unless there is a ride through. The impacts of the fault of the wind power plant are changed according to the location, the type of the fault, the setting of the protection relay, the wind generator type (if there is a ride through or not), the overall characteristic of the network power system, the load distance from the generator, the grid configuration (radial or ring), the method of compensation, and the control algorithm in the grid [23]. During the fault the characteristics of the DFIG are changed. The rotor current is increased (the current may exceed 2-3 times the rated value), this will lead to increase the DC-link voltage (it may reach 2-3 times the rated value), the GSC tries to stabilize the DC-voltage and this will lead to increase the GSC current (may reach up to $57 \%$ of the rated value), and finally the turbine will be exposed to oscillating torque and this will reduce the turbine life time. The separation of the wind turbine from the grid during the fault is not preferred as it may lead to a voltage collapse, so there must be a fault ride through to overcome these problems. The chopper module which will be connected in parallel to the dc-link may be used for increasing the normal range of the DFIG and smoothing the linked voltage during the imbalance conditions $[23,63]$.

\subsubsection{Some of the Used Control Schemes}

There are a various control schemes used nowadays for DFIG focusing on the active and reactive power. The control variables are the rotor voltage or current and the blade pitch angle. One of these control systems depends on the quadrature and direct components of the rotor current and blade pitch angle for controlling the speed, reactive and active power respectively. The second control system depends on the quadrature and direct components of the rotor voltage and blade pitch angle for controlling the activity, reactive power and the speed, respectively. The third control system is considered as a variant of the second control system in which there are two modes for the operation and so the speed is limited to its rated value by acting on the pitch angle. Control system schemes give the desired output but the third control system gives a higher reactive power when the wind farms maximizing the reactive power. The first and the second control system generate the reference power below the synchronous speed and so the rotor winding consumes active power, while the third control system generates power above the synchronous speed as a result it generates active power. At the power limitation, the output power for the first control system has a small variation, because of the pitch controller difficulty to control the output power. At down power regulation, the first and the second control systems give a similar performance, as they generate the reference power at the same rotational speed but, the third control system is different, because the turbine generates the reference power at the rated speed. Hence, the stator active power generated is less as compared with the other two controls [64].

Another voltage control strategy depends on both of converters on the grid and the rotor side to be in a coordinated manner in the DFIG to control the operation during the fault condition. The RSC is usually used as the main reactive power source but GSC is a supplementary one. During the fault conditions in case of DFIG the current in the stator increased rapidly as the stator is connected directly to the grid and this will increase the rotor current and voltage, as a result this increased power will increase the energized power in the dc link as there is a fault in the grid, as a result the rotor is protected by the crowbar resistance and in this case it is like a squirrel cage induction generator with an increased rotor resistance. In this case the GSC is used as a STATCOM and delivers a limited amount of reactive power to the grid but the RSG is connected to the impedances in the crowbar. These impedances improve the dynamic stability of the DFIG during the fault conditions but on the other hand will effect on the overall performance as the increased penetration of the wind farms [23].

Paper [65] described a new FMAC (flux magnitude angle controller) for the DFIG wind turbine to adjust the rotor voltage and the angle rotor for controlling the electric power. FMAC consists of AVR (for controlling the rotor voltage) and PSS (for controlling the rotor angle and used the stator electric power as its input signals). The use of the PSS shifted the eigenvalues to the left and this has a positive influence on the damping. For the rotor speeds close to the synchronization (for very small slip) DFIG control is limited, because the steady state rotor terminal voltage is affected by the slip value. At high value of the slip the rotor vector voltage is equal to the slip value times the internally generated vector voltage and as the magnitude of the internally generated voltage is approximately constant then the 
rotor voltage is proportional to the slip. At a low value of slip the magnitude of the rotor voltage is small and so the control for the DFIG is limited, the performance of the DFIG is near to the squirrel cage induction generator.

The voltage of the wind turbine during the fault and after the fault cleared improved by using a STATCOM; hence improve the system reliability and stability. The system voltage has no effect on the maximum compensating current; as a result the STATCOM is able to be operated at any capacity at low voltages and this enhances the flexibility of this device. The highest rating of a STATCOM the best recovery of the voltage during and after the fault removed but the overall cost will be increased[66, 67]. Papers [68, 69] describe a master control unit (MCU) to make a power schedule to reduce the effect of fluctuation of offshore wind energy and maintain the reliability of the power supply; this schedule may received by the transmission system operator (TSO) to use less wind power energy than it is available and so the control unit may be improved by making a good commitment and system management depending on the power forecasting. There two control units primary and overall (MCU). The primary is the single unit control (UCS) which is the control unit for each windmill.

\subsection{Equivalent Wind Farm Model}

The aggregation of the wind turbines will be easier if they receive the same wind and therefore generate the same output power. In this case the aggregating wind turbines, equal to the sum of the rated power of the individual wind turbines, and receive the same incoming wind. The equivalent wind turbine will present the same model of the individual wind turbines. However, the wind is not equal on all turbines. The wind farm may consist of many wind turbines arranged in rows (may be separated three or five times the rotor diameter at the same row) and column (may be separated five or three times the rotor diameter at the same column), hence the turbines at the same row may have the same wind but at the next row have a different wind from the previous because of the shadow and parking effect [70].

The aggregation of wind turbine was developed for both variable and fixed speed based on aggregating the power for each individual wind turbine (using 3 th order model for simplicity)and neglecting the turbulence (stochastic) term for wind speed signal model due to the smoothing effect of a large number of turbines and using sum assumptions (using the electrical power in case of variable speed instead of the mechanical power as compared to fixed speed, $\mathrm{Cp}$ is assumed to be constant and replace by its maximum value, and the non-linear rotor speed versus control characteristic is replaced by a first order one) [71].

For different operating conditions of wind speed the aggregation of wind turbines may be easily calculated if the output mechanical torque of the individual turbine is used instead of the output power and by summing these torques one can find the total torque and used it as an input to the equivalent generator system, thus gives the equivalent out- put power at different wind conditions [70]. Figure (7) shows the block diagram of the equivalent wind turbine model. The equivalent impedance of the aggregated series or parallel wind farm calculated by using the expression proposed in [30]. The wind farm control system consist of two controllers one for the power controller and the other for the dispatching controller that distribute the wind farm generation between the wind turbines and design the active and relative power for each wind turbine depending on the system operator [49]. There are different techniques for calculating the equivalent impedance.



Figure 7. Block diagram of the equivalent wind turbine.

\section{Tidal In-Stream Turbines}

There are five types of ocean energy among tidal barrages and tidal in-stream. Barrages energy like hydro energy and it has an effect on plants and animals lived in the estuary, also affect on the quality of water and the fixed cost of making a barrage component is very high. Tidal in-stream is an attractive source of energy and its speed can be changed by changing the features of the place. One advantage is that the density of seawater is high (800 times that of air) compared to air resulting in higher energy density, therefore smaller size and cheaper rotors are needed for the same power output. Marine turbines are slow in moving, hence they cause a few disturbances in the underwater habitat compared to high speed wind turbines and have no discernible audio noise [72-79]. Marine turbines have larger capacity factor than wind turbines, hence they are more economical. Tidal in-stream turbines have smaller sizes and can use a wide variety of topologies. One of these topologies is the vertical axis turbine with a synchronous generator, the generator can be put above or below the turbine and so its size is not constrained [80]. The following sections discuss the tidal in-stream integration, the characteristics of the tidal in-stream, the technology used and marine turbine modeling.

\subsection{Tidal In-stream Integration}

Tidal flow results in predictable energy output patterns and forecasting marine currents depend on data gathered for short periods of time (predictable to within 98\% accuracy,) while wind forecasting depends on data gathered over a longer period. The marine resource is easier to integrate in 
the electrical grid. The change of the weather doesn't affect on its production as it depends on the gravitational force of the molecules of the moon and the sun to the molecules of the earth and the rotation of the earth; this gravitational force may be described as $\mathrm{F}=\mathrm{K} \mathrm{M} \mathrm{m} / \mathrm{d}^{2}$, $\mathrm{m}$ (mass of the molecule of the earth), $\mathrm{M}$ (mass of the moon or sun), $\mathrm{d}$ (distance between the bodies), and $\mathrm{K}$ (universal constant of gravitation). There are two types of tide; spring tide (the speed of the spring tides varies from 3.5 to $4 \mathrm{~m} / \mathrm{s}$ ) which happens when the moon and the sun are in the same line and neap tide (the speed of the neap tides varies from 2 to $2.5 \mathrm{~m} / \mathrm{s}$ ) and this happens when the moon and the sun at right angles as shown in figure (8) and so they pull water at the sea at different directions [80].
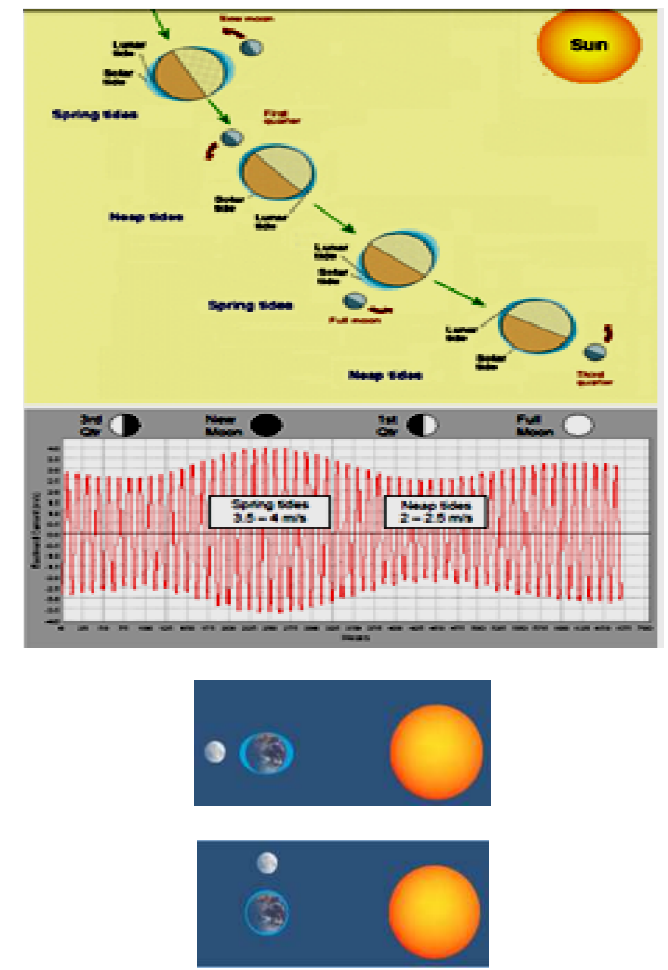

Figure 8. The power output during a spring and neap tide [83].

Some issues need to be considered in connecting marine generation into the grid such as intermittent, the effect of multi operation units, switch gear ratings during faults, plant size, generation mix, transmission line and cable thermal limits and quality of the power delivered including flickers, harmonics, and voltage sags. Reactive compensation may be required because using induction generators consume reactive power $(53-51 \%$ at idle and $60 \%$ of rated) [81].

Wind and tidal generation fluctuate during the day. Without storage, this causes cycling (turning on and off) of conventional stations causing thermal stresses on the boiler, steam lines, turbines and auxiliary components which lead to component damage. As the diameter of the turbine blade and the depth of the turbine increase the obtained energy from the tidal increased [73].

The distribution density of the tidal current energy is asymmetric everyday and so the electrical power from the tidal currents are unstable. Phase-locked-loop (PLL) as a control method which is a closed loop feedback control system is used to ensure that the grid-connected current and voltage have the same frequency and remain in phase with each other. The Phase Discriminator (PD) is used to monitor the phase difference between input and output signals. The Loop Filter (LF) is used as a filter for the noise and high frequency signals from $\mathrm{PD}$, and then the signals go from LF to Voltage Controlled Oscillator (VCO) which is used to adjust the frequency. If this method of control based on digital signal processing (DSP), this will give a good result and this circuit will be named as a synchronous PLL (SPLL). The integration of tidal power into the grid is still under investigation [82].

\subsection{Tidal In-stream Characteristics Compared To Off Shore Wind (The Advantages of Tidal In-stream Energy) [83, 84]}

1. It is a predictable source of energy, hence its generated energy is more valuable than from random source (wind, wave and solar), thus enhance the reliability of this source and has a lower impact on the efficiency.

2. It has a higher energy intensity, hence a smaller rotor as it compared to wind turbines for the same power rating (see figure (7) from which it was found that for $1 \mathrm{MW}$ generation the blade diameter for offshore wind turbine is 66 meters, for tidal current is 18 meter diameter and this will affect on the overall cost).

3. It has low environmental impact as it compared to other sources of energy.

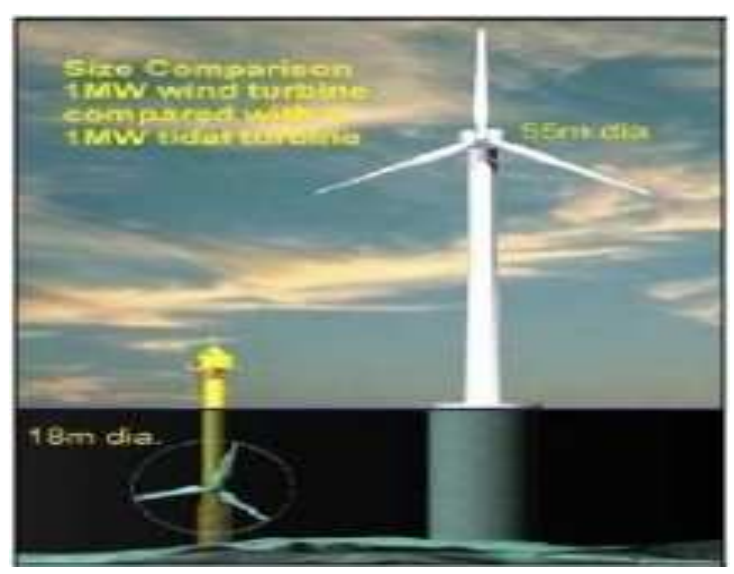

Figure 9. Wind turbine size versus tidal in-stream for the same rating (@MCT).

4. It has a turbine of much slower moving rotor and so will cause fewer disturbances for underwater survivals compared to the high speed for the wind turbines which will affect on the birds.

5. It causes very limited disturbances to shipping as its blade tip is immersed in the water at least $10 \mathrm{~m}$.

6. It has roughly four times the energy intensity as it compared to a good wind site, hence the tidal turbines need 
a quarter of the swept area of a wind turbine and this will reduce the cost of tidal turbines and also effects on the size of the place for putting this turbine.

7. It has no emissions of any polluted gas so it better for reducing the pollution.

8. It depends on data gathered in only one month with a great accuracy on the other hand wind depends on data gathered in two years.

9. It has greater capacity factor than the wind, so it is better for economics.

\subsection{Tidal In-stream Technologies}

Tidal in-stream turbines are under development, there are two types of these turbines depending on the axis of rotation horizontal axis (the axis of rotation is horizontal with respect to the ground and parallel to the flow direction) and vertical axis (the axis of rotation is perpendicular to the flow direction) [85].

There are various projects working on the development of tidal energy devices (TED) in the world and their progress is slow. From these projects MCT (Marine Current Turbines) which is ready for the use as shown in figure (7.a), apply the same technology as wind turbines and may use two turbines each has a rotor diameter between 15 and $22 \mathrm{~m}$ (the size depending on local site conditions), consists of twin axial flow rotors, each driving a generator connected to the turbine through a gear box and accommodated to work in bidirectional as their blades can be pitched through $180^{\circ}$. This technology is known as "SeaGen". The power units are easy to be raised above sea level for maintenance; this marine was tested in September 2005 and now they have a farm of turbines which may be used easily but still under development. The kinetic energy taken from water current depends on the square meters of flow crosssection, the water currents will drive the rotor at a speed of 10 and 22 revolutions per minute and this speed is slow to affect the lifetime of the blades [86].

1 MW prototype lunar energy turbine as shown figure (10.b) installed at the European Marine Energy Center in 2007 [87]. Figure (10c) shows another technology called an open hydro marine turbine technology [88]. Open hydro is one of the first energy technologies used in the world. The first test $(6 \mathrm{~m})$ produces energy to supply 153 average European homes and save 473 tones emission of $\mathrm{CO}_{2}$ each year.



a. MCT

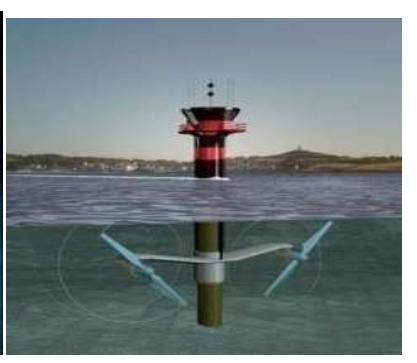

b. Lunar energy

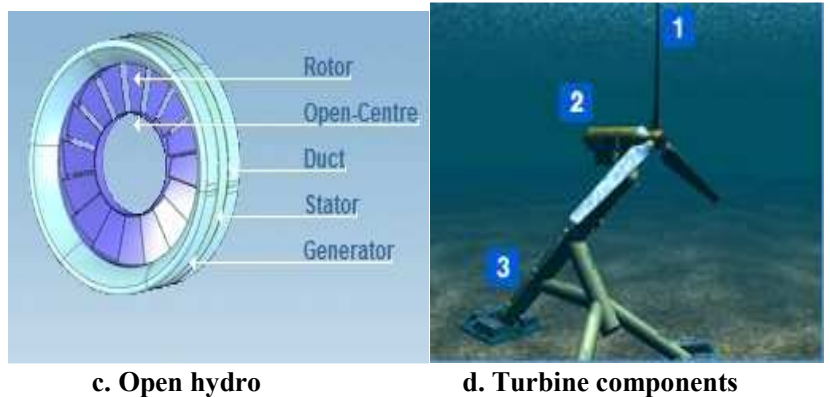

c. Open hydro

d. Turbine components

Figure 10. Some used technology (@MCT, @Openheydro)

The Engineering Business "Stingray" generator is another technology was developed in the United Kingdom and uses the oscillatory movement of hydroplanes driven by the water. The angle of the hydroplane is changed during the flowing of water (fall and rise) and the hydroplane is connected to a hydraulic cylinder. The movement will develop a pressure on the oil of a hydraulic cylinder; this pressure is used to drive a hydraulic motor which drives the electric generator.

The Hammerfest Stroem generator which has a horizontal axis prototype generator (similar to Seaflow project) was installed in Norwegian in 2003 to develop $310 \mathrm{~kW}$. North America (US and Canada) developed some small prototype technologies such as the Verdant Power and Underwater Electric Kite (UEK) [89].

The Rotech Tidal Turbine (RTT) is a prototype system tested to extract power from tidal currents into electrical power in a unique and patented manner. This prototype used a symmetric duct and turbine blade sections to operate in both directions and this eliminate the used mechanics part in a reversing tide. The turbine is connected to a fixed displacement hydraulic pump. This pump converts the rotational energy into hydraulic flow and pressure, then this fluid energy is fed to a sealed pod which is used to drive two variable displacement hydraulic motors and these motors drive a synchronous generator. By using the swashplate the power extracted from the generator is adjusted at various tidal conditions. This prototype system is designed to produce $1 \mathrm{MW}$ electrical power output at $11 \mathrm{KV}$ [90].

It was concluded that to get positive benefits for the tidal generation for a case studied in Ireland the capital cost must be less than 664,000 euro per MW installed and this is very high as it is comparable to conventional energy till now [91]. Figure (10.d) shows the main components of the turbine 1) shows the blade system; 2) The nacelle which is called also the production system contains the generator, gearbox and control system, and 3) shows the subsea cables which are used to transmit the electrical power from the off shore to the shore system. The turbine is able to work in two directions according to the direction of the flow.

Various types of turbines are now available horizontal axis (this consists of straight and inclined axis. The straight axis contains two types, solid mooring and buoyant mooring. The buoyant mooring may be submerged or nonsubmerged) and vertical axis (this consists of four types 
SC-Darrieus (Straight Blade), H-Darrieus (Straight Blade), Darrieus (Curved Blade), Gorlov (Helical Blade) and Savonius (Straight/Skewed)). Table (2) shows a comparison between vertical and horizontal axis rotor used with tidal current turbines. The horizontal axis turbine is preferred due to its easy control and has a high starting torque [89].

Table 2. a comparison between vertical and horizontal axis rotor.

\begin{tabular}{llll}
\hline No & Type of comparison & Vertical & Horizontal \\
\hline 1 & Design simplicity & Simple & Not simple \\
2 & Cost & $\begin{array}{l}\text { Less } \\
\text { Placed in one end } \\
\text { of the shaft and } \\
\text { may be above the } \\
\text { water surface }\end{array}$ & $\begin{array}{l}\text { High } \\
\text { angles gear coupling }\end{array}$ \\
3 & Generator coupling & High \\
4 & Noise emission & Less & Not easy \\
5 & $\begin{array}{l}\text { Floating and } \\
\text { augmentation }\end{array}$ & Easy & Face problems \\
6 & Skew flow & More suitable & High (self starting) \\
7 & Starting torque & Poor & Hasn't \\
8 & Output torque & Has ripple & High \\
9 & Efficiency & Low & Easy \\
10 & Control & Not easy & Hard \\
11 & Installation & Less hard & Well known as wind \\
12 & Knowing technology & Not well known & \\
\hline & & &
\end{tabular}

\subsection{Modeling of the Marine Turbines}

As discussed in the modeling of the wind turbines, the marine turbine modeling consist of the speed signals (resource), the rotor, the generator, and the control model.

1) The speed signals (resource) model: the tidal speed may be expressed as a function of the spring tide speed, neap tide speed and tides coefficient $(\mathrm{C})$, hence knowing tides coefficient, it is easy to derive a simple and practical model for tidal current speeds as follows:

$$
V_{\text {tide }}=V_{n t}+\frac{(C-45)+\left(V_{s t}-V_{n t}\right)}{95-45}
$$

, where: $V_{n t}$ is the neap tide speed and $V_{s t}$ is the spring tide speed, $\mathrm{C}=95$ for spring, 45 in neap tide [77].

2) The Rotor model: The tidal current power $\left(P_{t s}\right)$ may be found using the following equation: $\mathrm{P}_{\mathrm{ts}}=1 / 2 \rho \mathrm{A}$ (Vtide) $3, \rho$ is the density of the water $(1044 \mathrm{~kg} / \mathrm{m} 3)$, A is the crosssectional area perpendicular to the flow direction and $\mathrm{V}_{\text {tide }}$ is the velocity of the tidal in-stream. The marine turbines harness a fraction of this power, hence the power of the marine may be expressed as: $\mathrm{P}_{\mathrm{t}}=1 / 2 \rho \mathrm{C}_{\mathrm{p}} \mathrm{A}\left(\mathrm{V}_{\text {tide }}\right)^{3}, \quad \mathrm{Cp}$ is the marine turbine blade design constant in the range of $0.35-0.5$. The same model used for the offshore wind is used in tidal in-stream turbines; however, there is a number of differences in the design and operation of marine turbines due to the changes in force loadings, immersion depth, and different stall characteristics.
3) Dynamic modeling of the generator: The same dynamic modeling for the, DFIG used in the offshore wind [92, 93].

4) The control model: the tidal resource characteristics are nonlinear like turbulence and swell, also the inevitable uncertainties in DFIG based marine current turbines, and hence the need for nonlinear and robust control is of the requirements for marine turbines. One of the most popular nonlinear control methods is the higher order sliding mode (HOSM); this control method provides system dynamics with an invariant property to uncertainties [92].

\section{Hybrid Offshore Wind and Tidal In- Stream Turbine (HOTT)}

The simulations of the wind energy power and speed shows that wind power may lead to load problems at high levels of installed wind power if they used alone without any batteries and may destroy the stability of the grid.

Tidal in-stream and offshore wind generators use the same prime-moving principles, so a hybrid system of these two technologies may be very beneficial. Hybrid offshore wind and tidal-in-stream turbine systems (HOTT) are preferred because they offer flexible, stable, reliable and easy to use source of renewable energy. In some applications, the HOTT is connected electrically using a 6-pulse GTO rectifier to convert power to DC and then transmitted to shore using cables and again using a 6-pulse GTO inverter to convert the DC into AC and then connected to the grid using PWM control of the overall process $[2,5]$.

\section{Conclusion}

In this paper offshore wind turbines types were discussed, Different generator types were addressed, stability problems of wind turbines, mitigation methods, some control schemes and wind farm were shown as an introduction of the tidal current turbine. Then similarities and differences between tidal in-stream and offshore wind turbines, tidal in-stream technology and tidal in-stream turbine types were presented.

The wind is fluctuation and not easily predictable source of energy so the use of this source alone is not preferred. The hybrid of wind and other predictable or conventional source is more suitable. Since the techniques used in offshore wind turbines are approximately the same as the turbines used in the tidal in-stream (tidal current) so it is preferred to use a hybrid system of offshore wind and tidal current turbines and study its integration into the grid and its effect on the power system stability.

\section{References}

[1] José Luis Rodríguez, Santiago Arnalte, and Juan Carlos,' Automatic Generation Control of a Wind Farm With Variable Speed Wind Turbines" IEEE Transactions on Energy 
Conversion, Volume 17, No. 2, June 2002.

[2] Hamed H. Aly, and M. E. El-Hawary "An Overview of Offshore Wind Electrical Energy Systems" 23rd Annual Canadian IEEE Conference on Electrical and Computer Engineering, Calgary, Alberta, Canada, May 2-5, 2010.

[3] "Tidal Energy" Available online (January 2010), http://www.gcktechnology.com/GCK/Images/ms0032\%20fi nal.pdf.

[4] "Wave and Tidal Power" Available online (January 2010), http://www.fujitaresearch.com/reports/tidalpower.html.

[5] Hamed H. H. Aly, and M. E. El-Hawary "State of the Art for Tidal Currents Electrical Energy Resources", 24th Annual Canadian IEEE Conference on Electrical and Computer Engineering, Niagara Falls, Ontario, Canada, 2011.

[6] "Tidal Currents" Available online (April 2011), http://science.howstuffworks.com/environmental/earth/ocea nography/ocean-current $4 . h$ tm.

[7] Beach, and Bathurst "Generation of Electricity from Tidal Currents "Available online (January 2010), http://www.ipenz.org.nz/conventionCD/Documents/BeachBathurst.pdf.

[8] "Tidal Stream" Available online (January 2011), http://www.tidalstream.co.uk/html/background.html.

[9] "Tidal Currents" Available online (April 2011), http://science.howstuffworks.com/environmental/earth/ocea nography/ocean-current $4 . h$ tm.

[10] "New Marine Energy Roadmap Launched in Montreal", Available online (August 2012), http://www.nrcan.gc.ca/media-room/newsrelease/2011/3195

[11] "Nova Scotia Marine Renewable Energy Strategy ", Available online (August 2012), http://www.gov.ns.ca/energy/resources/publications/NovaScotia-Marine-Renewable-Energy-Strategy-May-2012.pdf.

[12] "Marine Renewable Energy Strategy" , Available online (August 2012) http://www.gov.ns.ca/energy/resources/publications/MarineRenewable-Energy-FAQs.pdf

[13] "Renewable Electricity Plan", Available online (August 2012),

http://www.gov.ns.ca/energy/resources/EM/renewable/renew able-electricity-plan.pdf.

[14] "Marine Renewable Energy Technology Roadmap", Available online (August 2012), http://oreg.ca/index.php?p=1_58_Marine-Energy-TRM.

[15] "Charting the Course Canada's Marine Renewable Energy Technology Roadmap" , Available online (August 2012), http://oreg.ca/web_documents/mre_roadmap_e.pdf.

[16] "Renewable Energy", , Available online (August 2012), http://www.nspower.ca/en/home/environment/renewableener gy/default.aspx.

[17] "Marine Renewable Energy Legislation for Nova Scotia" , Available online (August 2012), http://www.oreg.ca/web_documents/ns-mre.pdf.

[18] "Wave and Tidal Energy in UK", Available online (August
2012),

http://www.bwea.com/pdf/marine/Wave_Tidal_energy_UK. pdf.

[19] Abreu, L.V.L.; Shahidehpour, M.; "Wind Energy and Power System Inertia", Power Engineering Society General Meeting, IEEE 2006.

[20] Roth, H.; Kuhn, P.; Wagner, U.; "Effects of Wind Energy on Thermal Power Plants" Clean Electrical Power, ICCEP '07. International Conference on 40-42 May 2007 Page(s):683 665. Summary: Increasing wind energy use affects both existing power plants as well as future investments in the electricity market. Only a small contribution to total system reliability is added by wind energy. Part load operation and lower efficiency caused by t.

[21] José Luis Rodríguez-Amenedo, Santiago Arnalte, and Juan Carlos Burgos," Automatic Generation Control of a Wind Farm With Variable Speed Wind Turbines" IEEE Transactions on Energy Conversion, Volume 17, No. 2, June 2002.

[22] http://www.unihildesheim.de/ irwin/inside_wind_turbines.h tml.

[23] Anca D. Hansen, Gabriele Michalke, Poul Sørensen and Torsten Lund, Florin Iov "Co-ordinated Voltage Control of DFIG Wind Turbines in Uninterrupted Operation during Grid Faults", wind energy 2007. Published online 10 August 2006 in Wiley Interscience.

[24] Li Lin, Yan Zhang, Yihan Yang " Transient Characteristics of the Grid-connected Wind Power Farm with DFIGs and SCIGs" Electric Utility Deregulation and Restructuring and Power Technologies. DRPT 2008. Nanjuing, China.

[25] Johan Morren, , and Sjoerd W. H. de Haan, "Ride-through of Wind Turbines with Doubly-Fed Induction Generator During a Voltage Dip" IEEE Transactions on Energy Conversion, Vol. 37, No. 2, June 235.

[26] I. Erlich, , and F. Shewarega " Modeling of Wind Turbines Equipped with Doubly-Fed Induction Machines for Power System Stability Studies" Power and Energy Society General Meeting - Conversion and Delivery of Electrical Energy in the 21st Century, 2008 IEEE, Page(s): $1-8$.

[27] C. Ghită1, D. I. Deaconu1, A. I. Chirilă1, V. Năvrăpescu1 and D. Ilinal "Lab Model for a Low Power Wind Turbine System" International Conference on Renewable Energies and Power Quality (ICREPQ'09) Valencia (Spain), 15th to 17th April, 2009.

[28] J. G. Slootweg, S. W. H. de Haan, H. Polinder, and W. L. Kling, "General Model for Representing Variable SpeedWind Turbines in Power System Dynamics Simulations" IEEE Transactions on Power Systems, Vol. 18, No. 1, February 2003.

[29] Yazhou Lei, Alan Mullane, Gordon Lightbody, and Robert Yacamini "Modeling of the Wind Turbine with a Doubly Fed Induction Generator for Grid Integration Studies" IEEE Transaction on Energy Conversion, Vol. 28, No. 1, March 2006.

[30] Miguel Garcia-Gracia, M. Paz Comech, Jesus Sallan, Andres Liombart "Modelling wind farms for grid disturbance studies" Elsevier journal, 2008.

[31] Bingchang Ni, Constantinos Sourkounis, "Power Output Characteristics Analysis of Wind Energy Converter Control 
Methods" 13th International Power Electronics and Motion Control Conference (EPE-PEMC 2008).

[32] Fei Ye, Xueliang Huang, Chaoming Wang, Gan Zhou, Ping Luo " The impact and simulation on large wind farm connected to power system" Electric Utility Deregulation and Restructuring and Power Technologies. DRPT 2008. Nanjuing, China.

[33] Wei Qiao, Member, IEEE “Dynamic Modeling and Control of Doubly Fed Induction Generators Driven by Wind Turbines" IEEE Power \& Energy Society, March 15-18, 2009.

[34] Pavlos S. Georgilakis "Technical challenges associated with the integration of wind power into power systems"Elsevier journal, 2008.

[35] I. Erlich, , J. Kretschmann, S. Mueller-Engelhardt, F. Koch, J. Fortmann, "Modeling of Wind Turbines based on DoublyFed Induction Generators for Power System Stability Studies" Power and Energy Society General Meeting - Conversion and Delivery of Electrical Energy in the 28st Century, IEEE 2008

[36] Marcus V. A. Nunes, J. A. Peças Lopes, Hans Helmut Zürn, Ubiratan H. Bezerra, and Rogério G. Almeida "Influence of the Variable-Speed Wind Generators in Transient Stability Margin of the Conventional Generators Integrated in Electrical Grids" IEEE Transactions on Energy Conversion, Vol. 36, No. 4, December 2004.

[37] J.G. Slootweg, H. Polinder W.L. Kling, "Dynamic Modeling of a Wind Turbine with Doubly Fed Induction Generator" Power Engineering Society Summer Meeting, 2001, IEEE.

[38] Janaka B. Ekanayake, Lee Holdsworth, XueGuang Wu, and Nicholas Jenkins, " Dynamic Modeling of Doubly Fed Induction Generator Wind Turbines" IEEE Transactions On Power Systems, Vol. 18, No. 2, May 2003.

[39] Lucian Mihet-Popa, Frede Blaabjerg, and Ion Boldea," Wind Turbine Generator Modeling and Simulation Where Rotational Speed is the Controlled Variable" IEEE Transactions On Industry Applications, Vol. 58, No. 1, January/February 2004.

[40] Iov, F.; Blaabjergg, F.; Hansen, A.D.; Chen, Z. "Comparative study of different implementations for induction machine model in Matlab/Simulink for wind turbine simulations" Computers in Power Electronics, 2102. Proceedings.2102 IEEE Workshop on Volume, Issue, 3-4 June 2002 Page(s): $67-66$.

[41] L.M. Fernández, C.A. García, J.R. Saenz, F. Jurado "Equivalent models of wind farms by using aggregated wind turbines and equivalent winds" Elsevier journal, 2008.

[42] Hamed H. H. Aly, and M. E. El-Hawary "State of the Art for Tidal Currents Electrical Energy Resources", 24th Annual Canadian IEEE Conference on Electrical and Computer Engineering, Niagara Falls, Ontario, Canada, 2011.

[43] F. Wu, X.-P. Zhang, and P. Ju "Small signal stability analysis and control of the wind turbine with the direct-drive permanent magnet generator integrated to the grid" Journal of Electric Power and Engineering Research, 2009.

[44] Kala Meah; Yi Zhang; Sadrul Ula "Wind Energy Resources in Wyoming and Simulation for Existing Grid Connection" Power Systems Conference and Exposition. PSCE apos; 06. IEEE PES Volume, Issue, Oct. 2006-Nov. 2006
Page(s):3879 - 3883 .

[45] Vilchez, E.; Stenzel, J.;" Wind energy integration into 110 $\mathrm{kV}$ system Impact on power quality of MV and LV networks" Transmission and Distribution Conference and Exposition: Latin America, IEEE/PES 13-15 Aug. 2008 Page(s):1 - 6. Summary: The amount of electrical energy produced by wind farms is constantly increasing. Nowadays detailed analyses considering the impact of wind energy integration on the transmission system are required. Therefore several wind impact studies have been car.Mark L. Ahlstrom, and Robert M. Zavadil, "The Role of Wind Forecasting in Grid Operations \& Reliability" IEEE/PES Transmission and Distribution Conference \& Exhibition 2005: Asia and Pacific Dalian, China.

[47] Fox, B.; Flynn, D.;" Wind Intermittency - Mitigation Measures and Load Management" Power Tech, IEEE Russia 5255 June 2005 Page(s): 1 - 3.

[48] http://www.ewec3820proceedings.info/allfiles2/552_Ewec3 820fullpaper.pdf.

[49] Zhenyu Fan; Enslin, J.H.R.;" Wind Power Interconnection Issues in the North America" Transmission and Distribution Conference and Exhibition, IEEE PES May 2006 Page(s):561 - 568 .

[50] Pavlos S. Georgilakis "Technical challenges associated with the integration of wind power into power systems"Elsevier journal, 2008.

[51] Matevosyan, J.; "Wind power integration in power systems with transmission bottlenecks" Power Engineering Society General Meeting. IEEE June-2007-Page(s): 1-7. Summary: The best conditions for the development of wind farms are in remote, open areas with low population density. The transmission system in such areas might not be dimensioned to accommodate additional large-scale power infeed. Furthermore a part of the

[52] Karki, R.; Billinton, R.;" Cost-effective wind energy utilization for reliable power supply" Energy Conversion, IEEE Transaction on Volume 36, Issue 2, June 2004 Page(s):625622 .

[53] K. A. Folly and S. P. N. Sheetekela, "Impact of Fixed and Variable Speed Wind Generators on the Transient Stability of a Power System Network" Power Systems Conference and Exposition, IEEE/PES, 15-18 March 2009.

[54] Shuhui Li; Haskew, T.; Challoo, R. "Characteristic study for integration of fixed and variable speed wind turbines into transmission grid" Transmission and Distribution Conference and Exposition, 2008. T\&D. IEEE/PES Volume, Issue, 21-24 April 2008 Page(s):1 - 9.

[55] Eping, C.; Voelskow, M.;" Enhancement of the Probability of Occurrence for Off-Shore Wind Farm Power Forecast " Power Tech, IEEE Lausanne 1-5 July 2007 Page(s):642 646.

[56] Bingchang Ni; Sourkounis, C.; " Influence of Wind Energy Converter Control Methods on the Output Frequency Components" Industry Applications Society Annual Meeting. IAS '08. IEEE 5-9 Oct. 2008 Page(s): 1 - 7 .

[57] Abbey, C.; Joos, G.;" Coordination of Distributed Storage with Wind Energy in a Rural Distribution System" Industry Applications Conference. Conference Record of the 2007 IEEE 42-52 Sept. 2007 Page(s):1087 - 1092. 
[58] Voller, S.; Al-Awaad, A.-R.; Verstege, J.F.;" Benefits of energy storages for wind power trading" Sustainable Energy Technologies. ICSET. IEEE International Conference on 4352 Nov. 2008 Page(s): $702-706$.

[59] Hong Huang; Liuchen Chang "A New DC Link Voltage Boost Scheme of IGBT Inverters for Wind Energy Extraction" Electrical and Computer Engineering, Canadian Conference, Volume 1, 7-10 March 230 Page(s):679 - 683 vol.1.

[60] Muljadi, E. Mills, Z. Foster, R. Conto, J. Ellis, A. "Fault analysis at a wind power plant for one year of observation" Power and Energy Society General Meeting - Conversion and Delivery of Electrical Energy in the 21st Century, 2008 IEEE July 2008, page(s): 1-7.

[61] Salman K. Salman, Senior Member, IEEE, and Anita L. J. Teo "Windmill Modeling Consideration and Factors Influencing the Stability of a Grid-Connected Wind PowerBased Embedded Generator" IEEE Transactions On Power Systems, Vol. 18, No. 2, MAY 2003.

[62] Muljadi, E., Butterfield, C.P., Parsons, B., Ellis, A. "Characteristics of Variable Speed Wind Turbines Under Normal and Fault Conditions" Power Engineering Society General Meeting, 2007. IEEE Volume, Issue, 25-29 June 2007 Page(s):1 7.

[63] Erlich, I.; Wrede, H.; Feltes, C. "Dynamic Behavior of DFIG-Based Wind Turbines during Grid Faults" Power Conversion Conference - Nagoya, 2007. PCC '072-5 April 2007 Page(s): 1195 - 1200.

[64] L.M. Fernandez, C.A. Garcia, F. Jurado "Comparative study on the performance of control systems for doubly fed induction generator (DFIG) wind turbines operating with power regulation" Elsevier journal 2008.

[65] F. Michael Hughes, Olimpo Anaya-Lara, Nicholas Jenkins, and Goran Strbac "A Power System Stabilizer for DFIGBased Wind Generation" IEEE TRANSACTIONS ON POWER SYSTEMS, VOL. 21, NO. 2, MAY 2006.

[66] Aditya P. Jayam, Badrul H. Chowdhury "Improving the Dynamic Performance of Wind Farms With STATCOM" Power Systems Conference and Exposition, 2009. PES '09. IEEE/PES, 17 March 2009.

[67] Aditya P. Jayam, Nikhil K. Ardeshna, Badrul H. Chowdhury "Application of STATCOM for improved reliability of power grid containing a wind turbine" Power and Energy Society General Meeting - Conversion and Delivery of Electrical Energy in the 21st Century, 2008 IEEE 20-25 July 2008 Page(s): $1-7$.

[68] Eping, C.; Stenzel, J.;" Control of offshore wind farms for a reliable power system management" Power Tech, IEEE Russia 52-55 June 2005 Page(s): 1 - 4.

[69] http://www.icrepq.com/full-paper-icrep/539-Eping.pdf.Ch. Eping, J. Stenzel "Energy Management System for Offshore Wind Farms".

[70] Luis M. Fernandez, Francisco Jurado, Jose Ramon Saenz "Aggregated dynamic model for wind farms with doubly fed induction generator wind turbines" Elsevier Journal 2007.

[71] J.G. Slootweg, W.L. Kling, "Aggregated Modelling of Wind Parks in Power System Dynamics Simulations" IEEE Bologna Power Tech. Conference, June 23-26, 2003, Bologna, Italy.
[72] Sheth, S., Shahidehpour, M.;" Tidal energy in electric power systems" Power Engineering Society General Meeting. IEEE 12-16 June 2005 Page(s):682 - 687 Vol. 1.

[73] Bryans, A.G.; Fox, B.; Crossley, P.A.; O'Malley, M.; "Impact of tidal generation on power system operation in Ireland" Power Systems, IEEE Transactions on Volume 37, Issue 4, Nov. 2005 Page(s):3863 - 3862.

[74] Muljadi, E. Mills, Z. Foster, R. Conto, J. Ellis, A. "Fault analysis at a wind power plant for one year of observation" Power and Energy Society General Meeting - Conversion and Delivery of Electrical Energy in the 21st Century, 2008 IEEE July 2008, page(s): 1-7.

[75] Hammons, T.J.; "Tidal Power in the United Kingdom" Universities Power Engineering Conference, 61rd International 1-4 Sept. 2008 Page(s): 1 - 8

[76] Jones, A.T., Westwood, A. " Recent progress in offshore renewable energy technology development" Power Engineering Society General Meeting, IEEE 12-16 June 235, Vol. 2.

[77] S.E. Ben Elghali, M.E.H. Benbouzid, and J.F. Charpentier, "Marine Tidal Current Electric Power Generation Technology: State of the Art and Current Status" Electric Machines \& Drives Conference, IEMDC '07. IEEE International Volume 2, 3-5 May 2007 Page(s):1593 - 1595.

[78] Eleanor Denny, "The economics of tidal energy" Elsevier journal, Volume 62, Issue 5, May 2009, Pages 37143744.Hamed H. Aly "Forecasting, Modeling, and Control of Tidal currents Electrical Energy Systems"PhD thesis, Halifax, Canada, 2012.

[80] Smit, J.J.;" Trends in emerging technologies in power systems" Future Power Systems, International Conference on Nov. 2005 Page(s):7.

[81] http://www.pstidalenergy.org/Tidal_Energy_Projects/Misc/E PRI Reports and Presentations/EPRI-TP 001_Guidlines_Est_Power_Production_14Jun06.pdf. Summary: Tidal stream generation is a form of renewable energy that is predictable but variable in nature. The paper initially identifies the tidal resource around Ireland, utilizing the most appropriate and developed tidal energy technology, thus providing a.

[82] Salman, S.K.; Gibb, J.; Macdonald, I.;" Integration of tidal power based electrical plant into a grid" Universities Power Engineering Conference, 61rd International 1-4 Sept. 238 Page(s):1-4.

[83] Khan, J.; Bhuyan, G.; Moshref, A.; Morison, K.; Pease, J.H.; Gurney, J.; "Ocean wave and tidal current conversion technologies and their interaction with electrical networks" Power and Energy Society General Meeting - Conversion and Delivery of Electrical Energy in the 40st Century, IEEE 37-43 July 238 Page(s): 1 - 8. Summary: The environmental impacts of tidal stream energy extraction are not yet understood. What is known is that the ecological effects of tidal mixing are both direct and indirect. The direct effects of changes in mixing affect the location and timing of f.Hongda Liu, Dian-pu Li,Yao-hua Luo, Zhong-li Ma "The Gridconnection Control System of the Tidal Current Power Station", The 35rd Annual Conference of the IEEE Industrial Electronics Society (IECON), Nov. 5-8, 2007, Taipei, Taiwan. Summary: This paper presents a brief review of the state of ocean energy technologies, with special attention to 
ocean wave and tidal current systems. Schematic outline of a set of selected converter technologies is presented with a view to inferring their op.

[85] http://www.tidalgeneration.co.uk/background.html.

[86] http://www.johnarmstrong1.pwp.blueyonder.co.uk/CostEffe ctiveness.htm.

[87] http://oceanenergy.epri.com/attachments/streamenergy/repor ts/008_Summary_Tidal_Report_06-10-06.pdf.

[88] http://peswiki.com/index.php/Directory:Marine_Current_Tu rbines_Ltd\#How_it_Works.

[89] http://www.tidalstream.co.uk/html/background.html.
[90] http://www.openhydro.com/techOCT.html.

[91] M.J. Khan, G. Bhuyan, M.T. Iqbal, J.E. Quaicoe "Hydrokinetic energy conversion systems and assessment of horizontal and vertical axis turbines for river and tidal Elsevier journal applications: A technology status review" Applied Energy, Volume 86, Issue 10, October 2009, Pages 1824-1837.

[92] George Lemonis "Wave and Tidal Energy Conversion Encyclopedia of Energy", Elsevier journal 2004, Pages 405416. 